Д. В. Мелех, К. В. Гончар, И. П. Наркевич

РУП «Бел НИЦ «Экология»

\title{
ОПРЕДЕЛЕНИЕ ВЛИЯНИЯ НЕОПРЕДЕЛЕННОСТИ ВЫБРОСОВ ПАРНИКОВЫХ ГАЗОВ В СЕКТОРЕ «ЭНЕРГЕТИКА» НА ОБЩУЮ ОЦЕНКУ НЕОПРЕДЕЛЕННОСТИ ИНВЕНТАРИЗАЦИИ ВЫБРОСОВ И ПОГЛОЩЕНИЙ ПАРНИКОВЫХ ГАЗОВ В РЕСПУБЛИКЕ БЕЛАРУСЬ
}

Ежегодная инвентаризация выбросов и поглощения парниковых газов (ПГ), которая выполняется Республикой Беларусь в рамках обязательств по Рамочной Конвенции Организации Объединенных Наций об изменении климата (РКИК ООН), должна соответствовать ряду требований, среди которых оценки неопределенности, обеспечивающие полноту инвентаризации.

Цель: определение составляющих частей оценки неопределенности для сектора «Энергетика», таких как неопределенности коэффициентов выбросов и данных о деятельности с последующей оценкой неопределенности тренда и общей инвентаризации для определения влияния на них сектора «Энергетика».

Методы: Руководящие принципы Межправительственной группы экспертов по изменению климата (МГЭИК) 2006, а именно том 1 «Общие руководящие указания и отчетность» и том 2 «Энергетика», примененные с учетом национальных обстоятельств Республики Беларусь.

Результаты: впервые описаны и обоснованы неопределенности коэффициентов выбросов и данных о деятельности для сектора «Энергетика»; выполнены оценки неопределенности тренда и общей инвентаризации выбросов и поглощений парниковых газов для текущего года с обоснованием выбора подхода в проведении оценки неопределенности. Впервые оценено влияние сектора «Энергетика» на общую неопределенность.

Заключение: выполненные оценки неопределенности тренда и общей инвентаризации выбросов и поглощений парниковых газов обеспечивают соответствие требованиям РКИК ООН. Доля природного газа в энергетическом балансе страны составляет более $90 \%$, а коэффициент выбросов $\mathrm{CO}_{2}$ от его сжигания обладает низкой степенью неопределенности, что наряду с высокой развитостью системы государственной статистики организовывает снижение неопределенности общей инвентаризации.

Ключевые слова: парниковые газы, оценка неопределенности, коэффициенты выбросов, плотность распределения вероятности.

Для цитирования: Мелех Д. В., Гончар К. В., Наркевич И. П. Определение влияния неопределенности выбросов парниковых газов в секторе «Энергетика» на общую оценку неопределенности инвентаризации выбросов и поглощений парниковых газов в Республике Беларусь // Труды БГТУ. Сер. 2, Химические технологии, биотехнологии, геоэкология. 2021. № 1 (241). C. 211-227.

D. V. Melekh, K. V. Gonchar, I. P. Narkevitch RUE "BRC "Ecology"

\section{DETERMINATION OF THE INFLUENCE OF THE UNCERTAINTY OF GREENHOUSE GAS EMISSIONS IN THE "ENERGY" SECTOR ON THE OVERALL ASSESSMENT OF THE UNCERTAINTY OF THE GREENHOUSE GAS INVENTORY EMISSIONS AND REMOVALS IN THE REPUBLIC OF BELARUS}

The annual inventory of greenhouse gas (GHG) emissions and removals, which is carried out by the Republic of Belarus within the framework of the obligations under the United Nations Framework Convention on Climate Change (UNFCCC), should comply a number of requirements, including uncertainty estimates that ensure the completeness of the inventory.

Purpose: to identify the constituent parts of the uncertainty estimate for the Energy sector, such as the uncertainties of emission factors and activity data, followed by an assessment of the trend uncertainty and the general inventory uncertainty to determine the impact on it of the Energy sector. 
Methods: 2006 Intergovernmental Panel on Climate Change (IPCC) Guidelines, namely Volume 1 "General Guidance and Reporting" and Volume 2 "Energy", applied taking into account the national circumstances of the Republic of Belarus.

Results: uncertainties of emission factors and activity data for the Energy sector are described and substantiated for the first time; the assessment of the trend uncertainty and the general inventory uncertainty of GHG emissions and removals for the current year was carried out, with the justification of the choice of the approach to the uncertainty assessment. The impact of the "Energy" sector on the overall uncertainty was estimated for the first time.

Conclusion: the performed estimates of the trend uncertainty and the general inventory uncertainty of GHG emissions and removals ensure compliance with the UNFCCC requirements. The share of natural gas in the country's energy balance is more than $90 \%$, and the $\mathrm{CO}_{2}$ emission factor from its combustion has a low degree of uncertainty, which, along with a highly developed system of state statistics, organizes a reduction in the uncertainty of the general inventory.

Key words: greenhouse gases, uncertainty assessment, emission factors, probability density function.

For citation: Melekh D. V., Gonchar K. V., Narkevitch I. P. Determination of the influence of the uncertainty of greenhouse gas emissions in the "Energy" sector on the overall assessment of the uncertainty of the greenhouse gas inventory emissions and removals in the Republic of Belarus. Proceedings of BSTU, issue 2, Chemical Engineering, Biotechnologies, Geoecology, 2021, no. 1 (241), pp. 211-227 (In Russian).

Введение. Являясь стороной РКИК ООН, включенной в приложение 1 к Конвенции, Беларусь ежегодно, начиная с 2003 г., готовит инвентаризации выбросов и поглощений парниковых газов и направляет в секретариат Конвенции $[1,2,3]$. Инвентаризации выбросов и поглощений парниковых газов подлежат рассмотрению группой экспертов под руководством секретариата Конвенции, чтобы обеспечить получение достоверной информации Конференцией Сторон РКИК ООН, которая является верховным органом Конвенции. Ежегодные инвентаризации выбросов и поглощения парниковых газов должны соответствовать требованиям Руководящих принципов РКИК ООН для представления информации о годовых кадастрах парниковых газов [4], одним из требований является проведение оценки неопределенности. Группа экспертов, рассматривающих инвентаризации выбросов и поглощений парниковых газов, готовит отчет по результатам работы, где указывает на возможные несоответствия Руководящим принципам РКИК ООН для представления информации о годовых кадастрах парниковых газов, в том числе и на необходимость проведения оценки неопределенности $[5,6]$.

Основная часть. Согласно определению, оценки неопределенности - существенный элемент полного кадастра выбросов и поглощений парниковых газов. Они должны быть получены как для национального уровня, так и для оценки тенденции, так же как и для их составляющих частей, таких как коэффициенты выбросов, данные о деятельности и другие параметры оценки для каждой категории. Для достижения цели оценки неопределенности кадастра вы- бросов и поглощений парниковых газов на национальном уровне поставлены следующие задачи:

- определение неопределенности в индивидуальных переменных, используемых в кадастре (например, оценки выбросов от определенных категорий, коэффициентов выбросов, данных деятельности);

- соединение составляющих неопределенности в полный кадастр;

- определение неопределенности в тенденции;

- определение существенных источников неопределенности в кадастре, способствующее улучшению кадастра с помощью расположения собрания данных и усилий по улучшению кадастра по приоритетам.

Анализ неопределенности должен рассматриваться, прежде всего, как средство для приоритизации нацииональных усилий по уменьшению неопределенности кадастров $и$ принятия решения по выбору методологии.

По этой причине методы для оценки значений неопределенности должны быть:

- практичными;

- научно обоснованными;

- достаточно устойчивыми для применения к широкому диапазону категорий выбросов из источников и абсорбции поглотителями, а также методов и национальных обстоятельств.

Для комбинирования неопределенностей предлагаются два подхода. Подход 1 (распространение ошибок) - относительно простая процедура вычисления на основе крупноформатной таблицы, основанная на некоторых предположениях, чтобы упростить вычисления. Подход 2 (моделирование методом МонтеКарло) базируется на моделировании Монте- 
Карло и может применяться более широко. Каждый подход обеспечивает оценку всех неопределенностей, связанных с полным кадастром парниковых газов.

Принцип анализа методом Монте-Карло состоит в выборе случайных величин коэффициентов выбросов, данных о деятельности и других параметров оценки в пределах их индивидуальных плотностей распределения вероятностей $^{1}$ и в расчете соответствующих величин выбросов. Эту процедуру повторяют много раз (сотни и тысячи итераций), используя компьютер и специальное статистическое программное обеспечение, а результаты каждой итерации вычислений создают всеобъемлющую плотность распределения вероятностей выбросов. Анализ методом Монте-Карло можно проводить на уровне категории источника, для укрупненных категорий или для кадастра в целом.

Подход 2 является более приемлемым, чем подход 1, при оценке неопределенности выбросов и поглощений парниковых газов в случае, когда:

- неопределенности велики;

- распределение неопределенностей не является нормальным;

- алгоритмы являются сложными функциями;

- происходят корреляции между некоторыми из комплектов данных, коэффициентами выбросов или теми и другими;

- неопределенности различны для разных кадастровых лет.

В данной статье подробно рассмотрена оценка неопределенностей по подходу 1 , так как внимание направлено на влияния оценки неопределенности выбросов парниковых газов в секторе «Энергетика» на общую неопределенность инвентаризации выбросов и поглощений парниковых газов в Республике Беларусь. Исходные данные о деятельности, необходимые для расчета выбросов парниковых газов в секторе «Энергетика», в большей степени предоставляются Национальным статистическим комитетом Республики Беларусь [7]. Согласно Руководству по эффективной практике МГЭИК 2006, такие данные признаны достаточно точными, с низкими значениями неопределенности, принимая во внимание, что Беларусь имеет высокоорганизованную систему государственной статистики [8]. Расчет выбросов парниковых газов в секторе «Энергетика» представляет собой произведение коэффициента выбросов и данных о деятельности. Более

\footnotetext{
${ }^{1}$ Плотность распределения вероятности описывает диапазон и относительную вероятность возможных значений.
}

чем 97\% выбросов парниковых газов по сектору «Энергетика» составляют выбросы $\mathrm{CO}_{2}$ [9], а неопределенности коэффициентов выбросов $\mathrm{CO}_{2}$ относительно невелики и имеют нормальное распределение, эти коэффициенты выбросов определяются содержанием углерода в топливе. Нефтепродукты, как правило, соответствуют довольно жестким требованиям, ограничивающим возможный диапазон концентраций углерода и значений теплотворной способности, кроме того, они поставляются из относительно небольшого количества нефтеперерабатывающих предприятий и/или импортных терминалов. Уголь, напротив, может быть получен из угольных шахт, дающих уголь с очень широким диапазоном содержания углерода и значений теплотворной способности [10], однако потребление угля составляет менее $1 \%$ на производство тепловой и электрической энергии в стране [7]. Неопределенности исходных данных о деятельности и коэффициентов выбросов не различаются в разные годы временного ряда при подготовке инвентаризации выбросов и поглощений парниковых газов, что обусловлено использованием постоянных поставщиков исходных данных о деятельности и поставщиков основных видов топлива.

Подход 1 базируется на основе распространения ошибок и используется для оценки неопределенности отдельных категорий, для кадастра в целом и для тенденций между интересующим годом и годом базовым, которым для Республики Беларусь является 1990 г. [4].

Для оценки неопределенностей с использованием подхода 1 необходимо заполнение исходных данных на уровне категорий выбросов и поглощений парниковых газов, с разбивкой по газам в $\mathrm{CO}_{2}$-эквиваленте и использованием диапазонов неопределенности для данных о деятельности и коэффициентов выбросов в соответствии с руководством по эффективной практике по секторам: 1) энергетика; 2) промышленные процессы и использование продуктов (ППИП); 3) сельское хозяйство; 4) землепользование, изменение землепользования и лесное хозяйство (ЗИЗЛХ); 5) отходы.

Данная работа направлена на оценку неопределенности сектора «Энергетика», поэтому описание диапазонов неопределенности для данных о деятельности и коэффициентов выбросов будет представлено для этого сектора. Укрупнение категорий выбросов и поглощений парниковых газов выполнено в соответствии с предлагаемым уровнем укрупнения анализа ключевых категорий по подходу 1 (табл. 1) [11]. 
Предлагаемый уровень укрупнения категорий сектора «Энергетика» при проведении оценки неопределенности по подходу 1

\begin{tabular}{|c|c|c|c|}
\hline \multicolumn{2}{|c|}{$\begin{array}{l}\text { Категории источников и поглотителей, } \\
\text { оцениваемые в анализе ключевых категорий }\end{array}$} & \multirow{2}{*}{$\begin{array}{c}\text { Оцениваемые } \\
\text { газы }\end{array}$} & \multirow[t]{2}{*}{ Особые соображения } \\
\hline Код категории & Наименование категории & & \\
\hline 1A1 & $\begin{array}{l}\text { Деятельность, связанная со сжигани- } \\
\text { ем топлива - Энергетическая про- } \\
\text { мышленность }\end{array}$ & $\mathrm{CO}_{2}, \mathrm{~N}_{2} \mathrm{O}, \mathrm{CH}_{4}$ & $\begin{array}{l}\text { Разукрупнить до основных типов } \\
\text { топлива }\end{array}$ \\
\hline 1A2 & $\begin{array}{l}\text { Деятельность, связанная со сжигани- } \\
\text { ем топлива - Производственные от- } \\
\text { расли и строительство }\end{array}$ & $\mathrm{CO}_{2}, \mathrm{~N}_{2} \mathrm{O}, \mathrm{CH}_{4}$ & $\begin{array}{l}\text { Разукрупнить до основных типов } \\
\text { топлива }\end{array}$ \\
\hline $1 \mathrm{~A} 3 \mathrm{a}$ & $\begin{array}{l}\text { Деятельность, связанная со сжигани- } \\
\text { ем топлива - Транспорт - Граждан- } \\
\text { ская авиация }\end{array}$ & $\mathrm{CO}_{2}, \mathrm{~N}_{2} \mathrm{O}, \mathrm{CH}_{4}$ & Только внутренняя авиация \\
\hline $1 \mathrm{~A} 3 \mathrm{~b}$ & $\begin{array}{l}\text { Деятельность, связанная со сжигани- } \\
\text { ем топлива - Транспорт - Дорожные } \\
\text { перевозки }\end{array}$ & $\mathrm{CO}_{2}, \mathrm{~N}_{2} \mathrm{O}, \mathrm{CH}_{4}$ & - \\
\hline $1 \mathrm{~A} 3 \mathrm{c}$ & $\begin{array}{l}\text { Деятельность, связанная со сжигани- } \\
\text { ем топлива - Транспорт - Железные } \\
\text { дороги }\end{array}$ & $\mathrm{CO}_{2}, \mathrm{~N}_{2} \mathrm{O}, \mathrm{CH}_{4}$ & - \\
\hline $1 \mathrm{~A} 3 \mathrm{~d}$ & $\begin{array}{l}\text { Деятельность, связанная со сжигани- } \\
\text { ем топлива - Транспорт - Водный } \\
\text { транспорт }\end{array}$ & $\mathrm{CO}_{2}, \mathrm{~N}_{2} \mathrm{O}, \mathrm{CH}_{4}$ & $\begin{array}{l}\text { Разукрупнить до основных типов } \\
\text { топлива. Только внутренний водный } \\
\text { транспорт }\end{array}$ \\
\hline $1 \mathrm{~A} 3 \mathrm{e}$ & $\begin{array}{l}\text { Деятельность, связанная со сжигани- } \\
\text { ем топлива - Транспорт - Прочие } \\
\text { виды транспорта }\end{array}$ & $\mathrm{CO}_{2}, \mathrm{~N}_{2} \mathrm{O}, \mathrm{CH}_{4}$ & $\begin{array}{l}\text { Если данная категория - ключевая, } \\
\text { составитель кадастра должен опре- } \\
\text { делить, какие подкатегории являют- } \\
\text { ся значительными }\end{array}$ \\
\hline $1 \mathrm{~A} 4$ & $\begin{array}{l}\text { Деятельность, связанная со сжигани- } \\
\text { ем топлива - Прочие секторы }\end{array}$ & $\mathrm{CO}_{2}, \mathrm{~N}_{2} \mathrm{O}, \mathrm{CH}_{4}$ & $\begin{array}{l}\text { Разукрупнить до основных типов } \\
\text { топлива }\end{array}$ \\
\hline 1A5 & $\begin{array}{l}\text { Деятельность, связанная со сжигани- } \\
\text { ем топлива - Неопределенные виды }\end{array}$ & $\mathrm{CO}_{2}, \mathrm{~N}_{2} \mathrm{O}, \mathrm{CH}_{4}$ & $\begin{array}{l}\text { Разукрупнить до основных типов } \\
\text { топлива }\end{array}$ \\
\hline 1B1 & $\begin{array}{l}\text { Летучие выбросы от топлива - Твер- } \\
\text { дые виды топлива }\end{array}$ & $\mathrm{CO}_{2}, \mathrm{CH}_{4}$ & - \\
\hline 1B2a & $\begin{array}{l}\text { Летучие выбросы от топлива - Нефть } \\
\text { и природный газ - Нефть }\end{array}$ & $\mathrm{CO}_{2}, \mathrm{CH}_{4}$ & - \\
\hline $1 \mathrm{~B} 2 \mathrm{~b}$ & $\begin{array}{l}\text { Летучие выбросы от топлива - Нефть } \\
\text { и природный газ - Природный газ }\end{array}$ & $\mathrm{CO}_{2}, \mathrm{CH}_{4}$ & $\begin{array}{l}\text { Если данная категория - ключевая, } \\
\text { составитель кадастра должен опре- } \\
\text { делить, какие подкатегории являют- } \\
\text { ся значительными }\end{array}$ \\
\hline
\end{tabular}

Категории 1А1, 1А2, 1А4, 1А5 относятся к стационарному сжиганию топлива, и неопределенность исходных данных о деятельности в этих категориях будет составлять не более $5 \%$ для $\mathrm{CO}_{2}, \mathrm{CH}_{4}$ и $\mathrm{N}_{2} \mathrm{O}$ относительно всех видов топлива, так как Республика Беларусь имеет хорошо развитую статистическую систему, за исключением неопределенности данных о биомассе, которая составляет $20 \%$, поскольку данные по биомассе в качестве топлива не настолько достоверны, как данные по ископаемому топливу. При сжигании ископаемого топлива неопределенности коэффициентов выбросов $\mathrm{CO}_{2}$ относительно невелики, эти коэффициенты выбросов определяются содержанием в топливе углерода. Коэффициенты выбросов $\mathrm{CH}_{4}$ и в особенности $\mathrm{N}_{2} \mathrm{O}$ являются в значительной степени неопределенными. Высокую неопределенность коэффициентов выбросов можно объяснить отсутствием соответствующих измерений и последующего обобщения, неопределенностями в измерениях или недостаточным пониманием процесса выброса. Определено общее значение неопределенности, равное 7\% для коэффициентов выбросов $\mathrm{CO}_{2}$ в секторе «Энергетика», 50 и 90\% для $\mathrm{CH}_{4}$ и $\mathrm{N}_{2} \mathrm{O}$ соответственно $[10,12]$. Для стационарного сжигания природного газа неопределенность коэффициента выбросов $\mathrm{CO}_{2}$ составляет 3\%, поскольку используется национальный коэф- 
фициент и осуществлен переход на методологию 2 уровня $[13,14]$.

Категория 1А3 «Транспорт» относится к мобильному сжиганию топлива, неопределенность исходных данных о деятельности будет составлять не более $5 \%$. Неопределенность коэффициентов выбросов $\mathrm{CO}_{2}, \mathrm{CH}_{4}$ и $\mathrm{N}_{2} \mathrm{O}$ для различных категорий транспорта будет отличаться согласно руководству по эффективной практике «Мобильное сжигание топлива» (глава 3, том 2 Руководящих принципов МГЭИК 2006) [15]:

- Гражданская авиация - 5,0, 78,5 и $113,0 \%$ для $\mathrm{CO}_{2}, \mathrm{CH}_{4}$ и $\mathrm{N}_{2} \mathrm{O}$ соответственно;

- дорожные перевозки - 5,0, 50,0 и 90,0\% для $\mathrm{CO}_{2}, \mathrm{CH}_{4}$ и $\mathrm{N}_{2} \mathrm{O}$ соответственно;

- железные дороги - 5,0, 50,0 и 90,0\% для

$\mathrm{CO}_{2}, \mathrm{CH}_{4}$ и $\mathrm{N}_{2} \mathrm{O}$ соответственно;

- водный транспорт - 1,5, 50,0 и 90,0\% для

$\mathrm{CO}_{2}, \mathrm{CH}_{4}$ и $\mathrm{N}_{2} \mathrm{O}$ соответственно;

- прочие виды транспорта - 5,0, 50,0 и $90,0 \%$ для $\mathrm{CO}_{2}, \mathrm{CH}_{4}$ и $\mathrm{N}_{2} \mathrm{O}$ соответственно.

Неопределенность коэффициента выбросов $\mathrm{CO}_{2}$ в категории «Мобильное сжигание топлива», как правило, не превышает $5 \%$, это обусловлено высокими требованиями к качеству топлива, используемого в транспорте. Диапазон неопределенности коэффициентов выбросов $\mathrm{CO}_{2}$ по умолчанию для дорожного транспорта - не более $5 \%$, к примеру, для дизельного топлива $-1,5 \%$.

Категория 1.В относится к летучим выбросам от топлив. Летучие выбросы - это случайные или намеренные высвобождения парниковых газов, которые могут происходить при добыче, обработке и доставке ископаемых видов топлива до места конечного использования. Для систем обращения с нефтью и природным газом точность для отдельных компонентов, как правило, составляет $\pm 5 \%$. Учитывая хорошо развитую статистическую систему Беларуси, принят показатель неопределенности данных о деятельности, равный 5\%. Значения неопределенностей коэффициентов выбросов парниковых газов для категории «Летучие выбросы от нефти и природного газа» определены на основании набора значений по умолчанию, где делалось допущение о нормальном распределении величин в предложенном диапазоне, после чего вычислялось среднее для предложенного диапазона значение неопределенности [16]:

- добыча нефти - 406,3\%;

- транспортировка нефти - 125,0\%;

- переработка и хранение нефти - 100,0\%;

- добыча, транспортировка и хранение природного газа - $145,0 \%$;

- распределение природного газа - 260,0\%;

- удаление природного газа - 75,0\%;

- транзит природного газа $-145,0 \%$.
Инвентаризации выбросов и поглощений парниковых газов Республики Беларусь 2016 г. и 2018 г. были использованы в качестве источников значений неопределенности данных о деятельности и коэффициентов выбросов для секторов 2 (ППИП), 3 (сельское хозяйство), 4 (ЗИЗЛХ) и 5 (отходы) $[17,18]$.

Анализ подхода 1 оценивает неопределенности с использованием уравнения, подверженного распространению ошибок, в два шага. Уравнение аппроксимации (1) используется для объединения коэффициента выбросов, данных о деятельности и других оценочных параметров по категориям и парниковым газов. Уравнение аппроксимации (2) используется для расчета общей неопределенности национальных выбросов и тенденции выбросов от базового года к году текущему:

$$
U_{\text {общ }}=\sqrt{U_{1}^{2}+U_{2}^{2}+U_{n}^{2}},
$$

где $U_{\text {общ }}-$ неопределенности в процентах произведения величин (половина 95\%-ного доверительного интервала, разделенная на сумму и выраженная в процентах); $U_{i}$ - неопределенности в процентах, связанные с каждой величиной;

$$
U_{\text {общ }}=\frac{\sqrt{\left(U_{1} x_{1}\right)^{2}+\left(U_{2} x_{2}\right)^{2}+\ldots+\left(U_{n} x_{n}\right)^{2}}}{\left|x_{1}+x_{2}+\ldots+x_{n}\right|},
$$

где $U_{\text {общ }}-$ неопределенности в процентах суммы величин (половина 95\%-ного доверительного интервала, разделенная на сумму (т. е. средняя величина) и выраженная в процентах), термин «неопределенность», таким образом, базируется на 95\%-ном доверительном интервале; $x_{i}$ и $U_{i}$ - соответственно неопределенные величины и связанные с ними неопределенности в процентах.

Для расчета неопределенностей используется таблица, колонки которой помечены буквами от А до М и содержат следующую информацию (табл. 2).

А и В показывают категорию МГЭИК и парниковый газ.

$\mathrm{C}$ и D являются оценками кадастра соответственно в базовый год и в текущий год ${ }^{2}$ для категории источника и газа, определенных в колонках А и В, выраженными в эквиваленте $\mathrm{CO}_{2}$.

$\mathrm{E}$ и $\mathrm{F}$ содержат неопределенности соответственно для данных о деятельности и коэффициентов выбросов, полученные из сочетания эмпирических данных и экспертных оценок,

\footnotetext{
${ }^{2}$ Текущий год - это самый недавний год, для которого имеются данные кадастра.
} 
введенные в качестве половины 95\%-ного доверительного интервала, разделенной на среднюю величину и выраженной в процентах. Причина разделения пополам 95\%-ного доверительного интервала состоит в том, что величина, введенная в колонки $\mathrm{E}$ и $\mathrm{F}$, затем соответствует близким величинам плюс и минус, когда неопределенности приближенно упоминаются как «плюс или минус $x \%$ », поэтому экспертные оценки этого типа могут быть непосредственно введены в таблицы для расчета. Если известно, что неопределенность имеет сильно асимметричный характер, вводится более крупное процентное различие между средней величиной и границей доверительного интервала данных в колонках Е и F с использованием уравнения объединения аппроксимации (2). Поэтому данные колонки G представляют собой квадратный корень из суммы квадратов показателей в колонках Е и $\mathrm{F}$.

Н показывает неопределенность в колонке $\mathrm{G}$ в виде процента от суммарных национальных выбросов за текущий год. Показатель в каждом ряду колонки $\mathrm{H}$ представляет собой квадрат показателя в колонке $\mathrm{G}$, умноженный на квадрат показателя в колонке D, разделенный на итоговую величину внизу колонки D. Итоговая величина внизу колонки Н представляет собой оценку неопределенности суммарных национальных выбросов за текущий год в процентах, рассчитанную на основе вышеприведенных показателей с использованием уравнения аппроксимации 1. Эта итоговая величина получена путем суммирования показателей в колонке Н и извлечения квадратного корня из суммы.

I показывает, как изменяется разность выбросов в процентах между базовым годом и текущим годом в ответ на однопроцентное увеличение выбросов/поглощений из категории источников как в базовом, так и в текущем году. Колонка показывает чувствительность тенденции выбросов к систематической неопределенности в оценках выбросов (т. е. корреляцию между базовым годом и текущим годом) - это чувствительность типа А. Чувствительность типа $A$ - это выраженное в процентах изменение разности общих выбросов между базовым годом и текущим годом в результате $1 \%$-ного увеличения выбросов или поглощений данной категории источника и газа как в базовый год, так и в текущий год.

J показывает, как изменяется разность выбросов в процентах между базовым годом и текущим годом в ответ на однопроцентное увеличение выбросов/поглощений из категории источника только в текущем году. Колонка демонстрирует чувствительность тенденции вы- бросов к случайной ошибке в оценке выбросов (т. е. чувствительность, которая не коррелируется между базовым годом и текущим годом) это чувствительность типа В. Чувствительность типа $B$ - это изменение различия общих выбросов между базовым годом и текущим годом, выраженное в процентах, в результате $1 \%$-ного увеличения выбросов или поглощений данной категории источника и газа только в текущий год.

$\mathrm{K}$ использует информацию в колонках I и $\mathrm{F}$ для демонстрации неопределенности, вводимой в тенденцию выбросов неопределенностью коэффициента выбросов, исходя из предположения, что неопределенность в коэффициентах выбросов коррелируется между годами. Если пользователь решает, что неопределенности коэффициентов выбросов не коррелируются между годами, то вместо колонки I должны использоваться показатели в колонке J, а результат должен умножаться на $\sqrt{2}$.

$\mathrm{L}$ использует информацию в колонках $\mathrm{J}$ и $\mathrm{E}$ для демонстрации неопределенности, вводимой в тенденцию выбросов неопределенностью данных о деятельности, исходя из предположения, что неопределенность в данных о деятельности не коррелируется между годами. Если пользователь решает, что неопределенности данных о деятельности коррелируются между годами, то вместо колонки J должны использоваться показатели в колонке I, а коэффициент $\sqrt{2}$ не применяется.

М представляет собой оценку неопределенности, вводимой в тенденцию национальных выбросов рассматриваемой категорией источника. При уровне 1 этот показатель выводят из данных в колонках $\mathrm{K}$ и L, используя уравнение объединения аппроксимации 2. Таким образом, показатель в колонке М является квадратным корнем из суммы квадратов величин в колонках K и L. Итоговая величина внизу этой колонки является оценкой суммарной неопределенности тенденции, рассчитанной на основе величин, приведенных выше, с использованием уравнения распространения ошибки. Эта итоговая величина получена путем суммирования показателей в колонке М и извлечения квадратного корня из суммы. Неопределенность тенденции является диапазоном процентного пункта по отношению к тенденции в кадастре. Например, если выбросы текущего года на 10\% превышают выбросы базового года, и если отчетная неопределенность тенденции внизу колонки М равна 5\%, то неопределенность тенденции составляет $(10 \pm 5) \%$ (или увеличение от 5 до 15\%) для выбросов текущего года относительно выбросов базового года. 


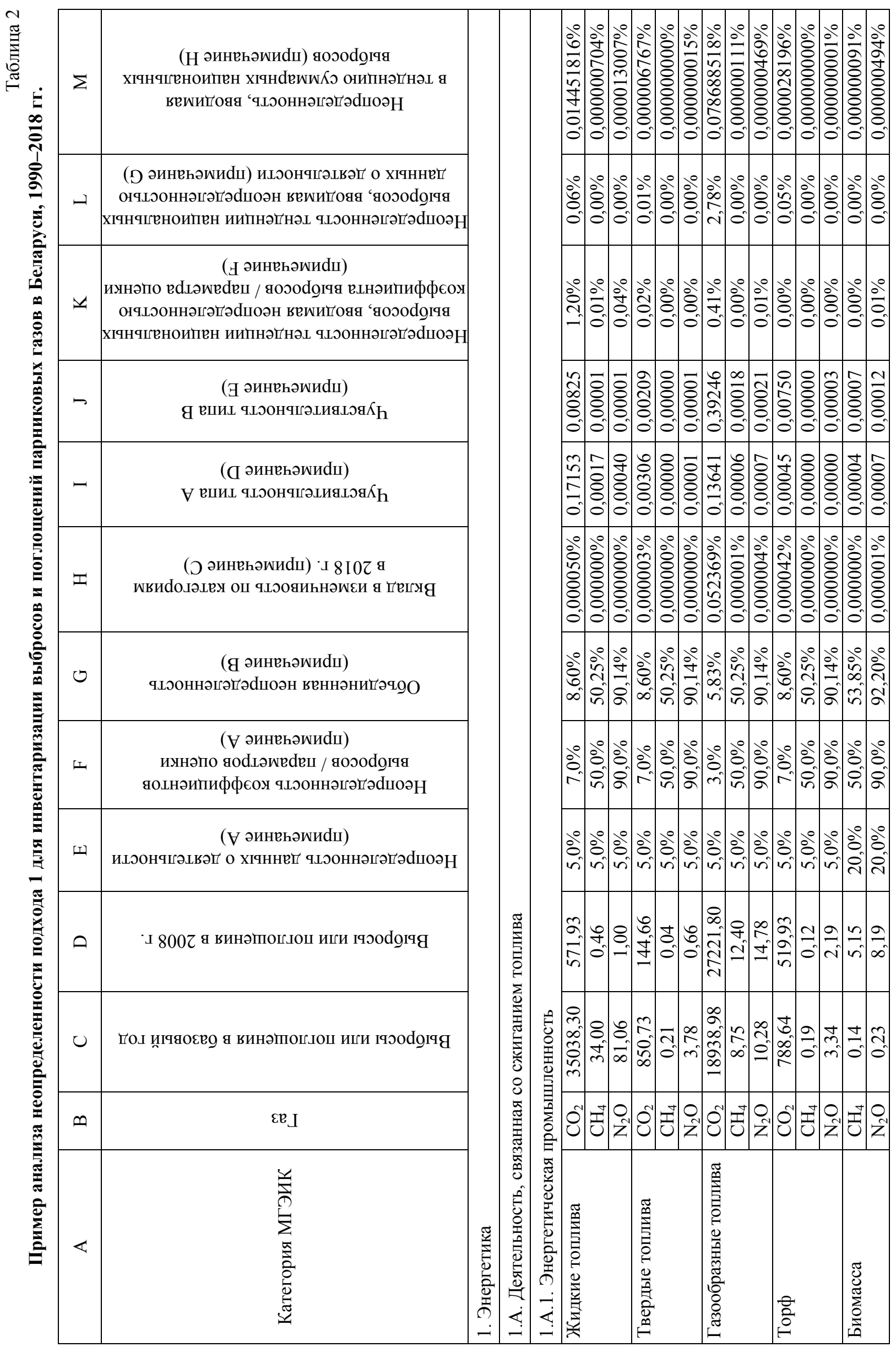

Труды БГТУ Серия 2 № 12021 


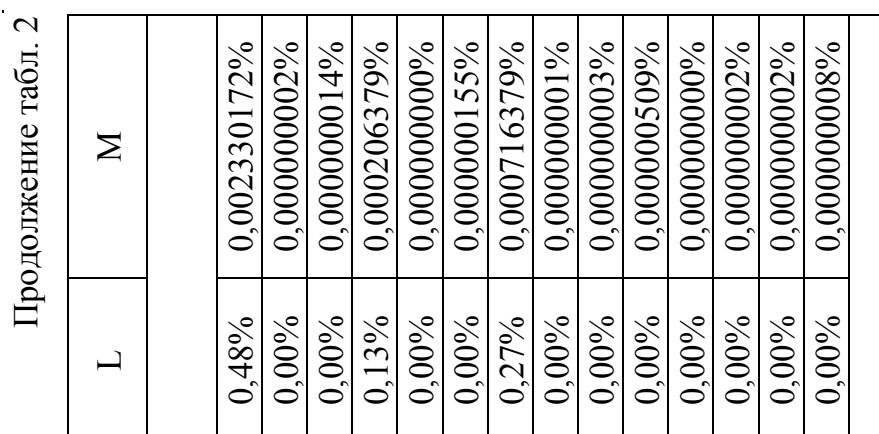

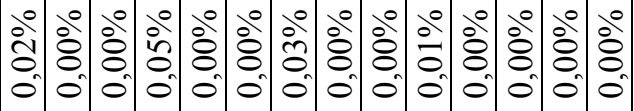

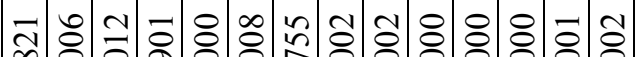
ஓे

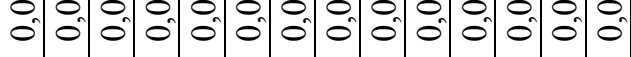

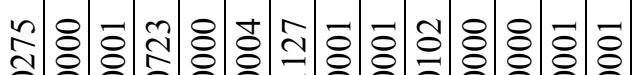
సै

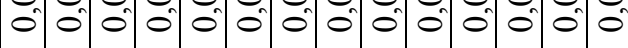

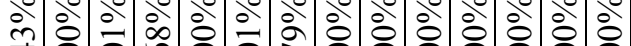
宅

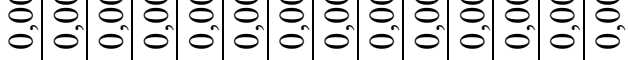

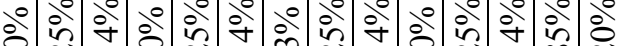
కి సె

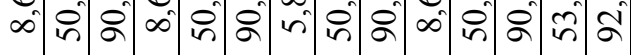

ठे ठํ.

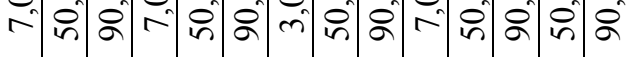

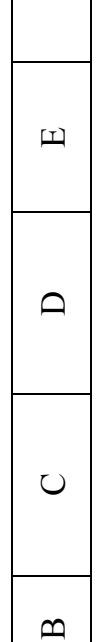

$\infty$

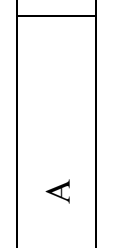

வㅇำ

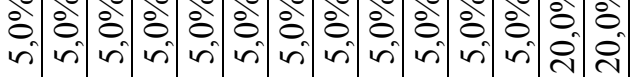

m.

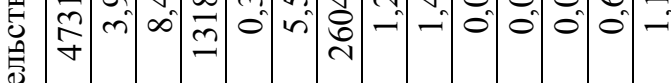

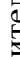

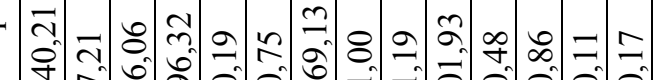

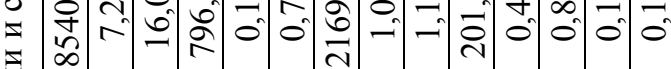
需

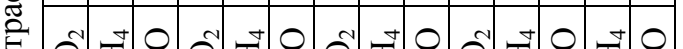

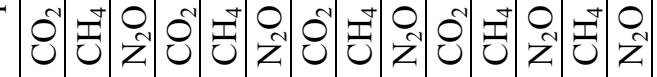

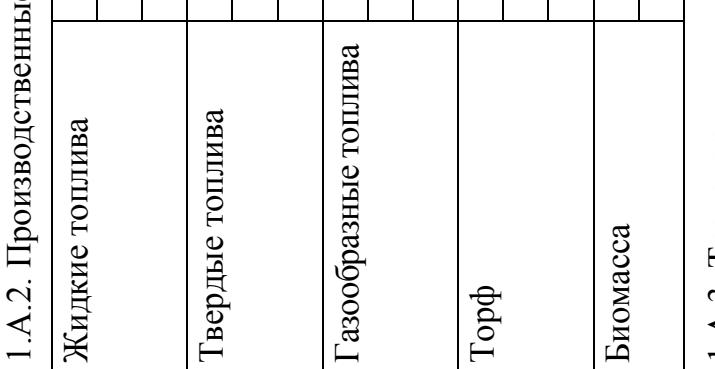

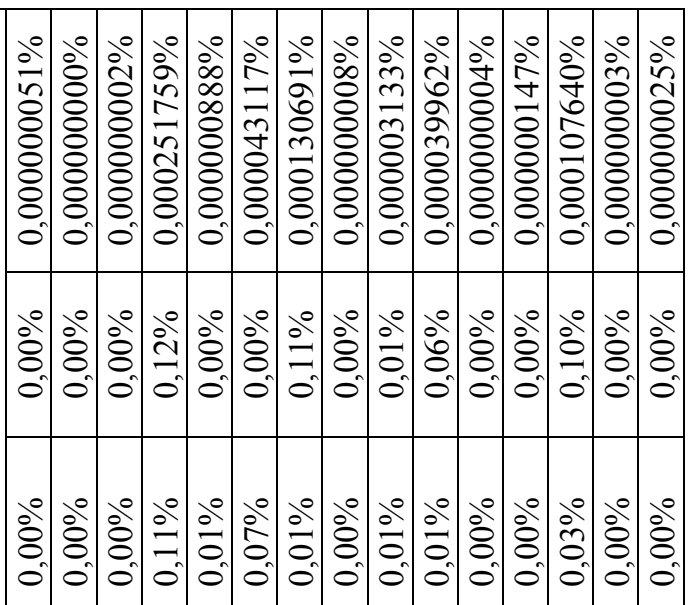

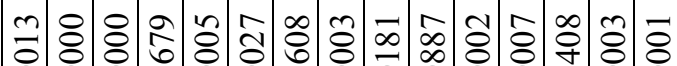
ঃे

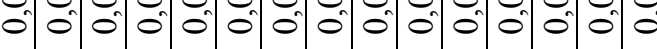

พ \& \& ঃ.

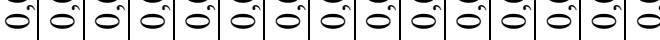

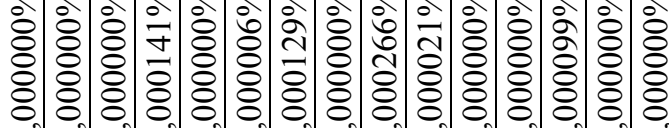

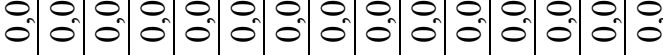

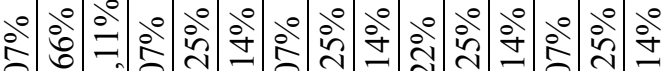

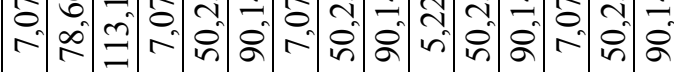
ठำ nी

ठे ni in in in in in in in in in

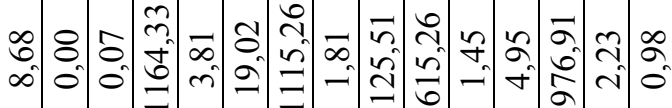

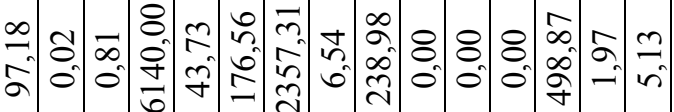

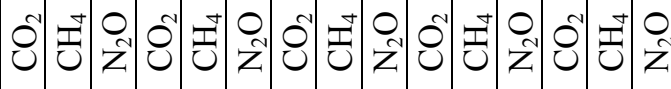

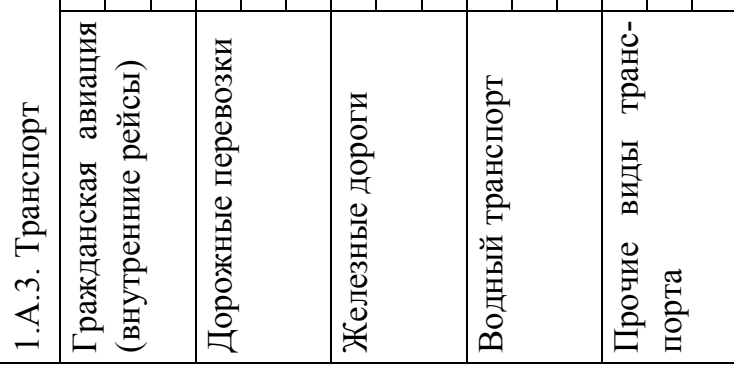




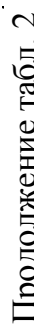

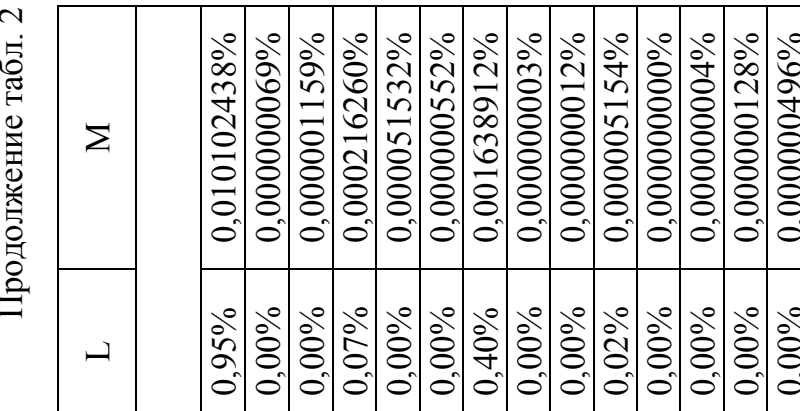

$\underline{1}$

సి.

\begin{tabular}{|c|c|c|c|c|c|c|c|c|c|c|c|c|c|c|}
\hline$\sim$ & $\begin{array}{c}0 \\
0 \\
\pm \\
2 \\
0 \\
0\end{array}$ & $\mid \begin{array}{l}\frac{ \pm}{8} \\
8 \\
0 \\
0\end{array}$ & $\begin{array}{l}\text { No } \\
\text { } \\
\delta \\
0 \\
0 \\
0\end{array}$ & $\frac{\tilde{\sigma}}{0}$ & $\begin{array}{l}1 \\
8 \\
8 \\
8 \\
0\end{array}$ & $\mid \begin{array}{l}\text { ஜ } \\
8 \\
8 \\
8 \\
0\end{array}$ & $\begin{array}{l}\bar{n} \\
6 \\
0 \\
0 \\
0\end{array}$ & 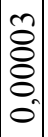 & 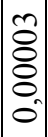 & $\begin{array}{c}\hat{N} \\
\text { ป̂. } \\
\delta \\
\delta \\
0\end{array}$ & 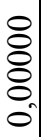 & $\mid \begin{array}{l}\overline{8} \\
8 \\
8 \\
8 \\
0\end{array}$ & $\mid \begin{array}{l}7 \\
\overline{8} \\
8 \\
8 \\
0\end{array}$ & $\begin{array}{l}\frac{\infty}{0} 8 \\
\\
0\end{array}$ \\
\hline- & $\begin{array}{l}0 \\
6 \\
5 \\
0 \\
0\end{array}$ & $\begin{array}{l}n \\
8 \\
8 \\
0 \\
0 \\
0\end{array}$ & $\begin{array}{l}2 \\
0 \\
8 \\
0 \\
0 \\
0\end{array}$ & $\begin{array}{l}\hat{\Upsilon} \\
\infty \\
0 \\
0\end{array}$ & $\frac{\mathfrak{m}}{\stackrel{8}{8}}$ & $\mid \begin{array}{l}\infty \\
\wp \\
\wp \\
\wp \\
0 \\
0\end{array}$ & 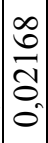 & $\mid \begin{array}{l}\overline{5} \\
8 \\
8 \\
\circ \\
0\end{array}$ & $\mid \begin{array}{l}\overline{8} \\
8 \\
8 \\
8 \\
0\end{array}$ & $\mid \begin{array}{c}0 \\
0 \\
0 \\
0 \\
0 \\
0\end{array}$ & 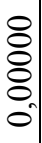 & $\mid \begin{array}{l}\overline{8} \\
8 \\
8 \\
8 \\
0\end{array}$ & $\mid \begin{array}{l}\text { m. } \\
8 \\
8 \\
8 \\
0 \\
0\end{array}$ & $\begin{array}{l}\circ \\
8 \\
8 \\
8 \\
0 \\
0\end{array}$ \\
\hline$I$ & 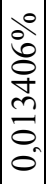 & $\begin{array}{l}0 \\
\delta \\
\delta \\
\delta \\
\delta \\
0 \\
0 \\
0\end{array}$ & $\begin{array}{l}0 \\
0 \\
0 \\
0 \\
8 \\
\delta \\
0 \\
0 \\
0\end{array}$ & $\begin{array}{l}0 \\
0 \\
0 \\
\delta \\
\delta \\
0 \\
0 \\
0\end{array}$ & $\begin{array}{l}\stackrel{\circ}{\circ} \\
\frac{8}{8} \\
8 \\
0\end{array}$ & $\begin{array}{l}0 \\
8 \\
8 \\
8 \\
8 \\
8 \\
0 \\
0\end{array}$ & $\begin{array}{l}0 \\
0 \\
0 \\
0 \\
0 \\
0 \\
8 \\
0 \\
0\end{array}$ & $\begin{array}{l}0 \\
8 \\
8 \\
8 \\
8 \\
8 \\
8 \\
0\end{array}$ & $\mid \begin{array}{l}0 \\
8 \\
8 \\
8 \\
8 \\
8 \\
8 \\
0 \\
0\end{array}$ & $\begin{array}{l}0 \\
0 \\
0 \\
0 \\
8 \\
8 \\
8 \\
0 \\
0\end{array}$ & $\begin{array}{l}0 \\
8 \\
8 \\
8 \\
8 \\
8 \\
8 \\
0\end{array}$ & $\begin{array}{l}0 \\
8 \\
8 \\
8 \\
8 \\
8 \\
8 \\
0\end{array}$ & $\mid \begin{array}{l}\circ \\
8 \\
8 \\
8 \\
8 \\
8 \\
8 \\
0 \\
0\end{array}$ & $\begin{array}{l}\text { ○े } \\
\text { ஸे } \\
\text { } \\
8 \\
8 \\
0\end{array}$ \\
\hline 0 & $\begin{array}{l}\delta^{0} \\
8 \\
\infty^{\circ} \\
0\end{array}$ & $\begin{array}{l}\text { o̊ } \\
\text { in } \\
\text { ñ } \\
\text { in }\end{array}$ & 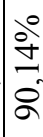 & $\mid \begin{array}{l}0 \\
8 \\
0 \\
\infty\end{array}$ & $\begin{array}{l}\stackrel{0}{n} \\
\text { in } \\
\text { in } \\
\text { in }\end{array}$ & $\frac{\partial^{\circ}}{\stackrel{ \pm}{\Xi}}$ & 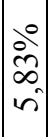 & 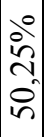 & 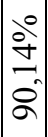 & $\mid \begin{array}{c}0 \\
0 \\
\delta \\
0 \\
\infty\end{array}$ & 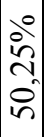 & 导 & $\mid \begin{array}{l}0 \\
i n \\
\infty \\
n \\
n \\
n\end{array}$ & 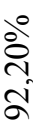 \\
\hline L & $\begin{array}{l}\stackrel{0}{0}^{2} \\
\mathrm{O}^{2}\end{array}$ & $\mid \begin{array}{l}00 \\
0 \\
0 \\
0 \\
\delta\end{array}$ & $\begin{array}{l}0 \\
8 \\
0 \\
8\end{array}$ & $\stackrel{0}{0}_{0}^{\circ}$ & $\begin{array}{l}\stackrel{0}{0} \\
0 \\
0 \\
0\end{array}$ & $\mid \begin{array}{l}0 \\
8 \\
0 \\
8\end{array}$ & $\begin{array}{c}0 \\
0 \\
0 \\
0 \\
m\end{array}$ & 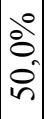 & $\begin{array}{l}\circ \\
8 \\
0 \\
8 \\
8\end{array}$ & $\mid \begin{array}{l}0 \\
0_{0} \\
0 \\
r\end{array}$ & $\begin{array}{l}0 \\
8 \\
0 \\
0 \\
n\end{array}$ & $\begin{array}{l}0 \\
8 \\
0 \\
8 \\
8\end{array}$ & $\mid \begin{array}{l}0 \\
8 \\
0 \\
0 \\
n\end{array}$ & 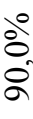 \\
\hline II & $\begin{array}{l}\stackrel{0}{ } \\
0^{\prime} \\
\text { in }\end{array}$ & $\stackrel{8}{0}_{i}^{0}$ & $\stackrel{8}{0}_{0}^{0}$ & $\begin{array}{c}0 \\
0 \\
0\end{array}$ & $\begin{array}{l}\stackrel{0}{0} \\
\text { in }\end{array}$ & $\stackrel{8}{0}^{\circ}$ & $\mid \begin{array}{c}0 \\
\delta^{0} \\
\text { in }\end{array}$ & $\begin{array}{l}0 \\
0 \\
0 \\
\text { ñ }\end{array}$ & $\begin{array}{l}\partial_{0}^{0} \\
i \\
i\end{array}$ & $\mid \begin{array}{l}0 \\
0^{0} \\
n \\
n\end{array}$ & $\begin{array}{l}\partial_{0}^{0} \\
0^{\prime} \\
\text { | }\end{array}$ & $\begin{array}{l}\partial^{0} \\
0 \\
n\end{array}$ & 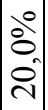 & $\begin{array}{l}\stackrel{0}{\delta^{2}} \\
\text { ᄋ̊ }\end{array}$ \\
\hline & $\begin{array}{l}\infty \\
\infty \\
n\end{array}$ & & & & $\begin{array}{l}n \\
\text { nn } \\
0\end{array}$ & ํ. & ñ & $\infty$ & & & 0 & $\infty$ & $\begin{array}{l}\infty \\
0 \\
0\end{array}$ & $\bar{N}$ \\
\hline
\end{tabular}

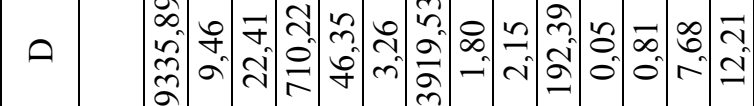

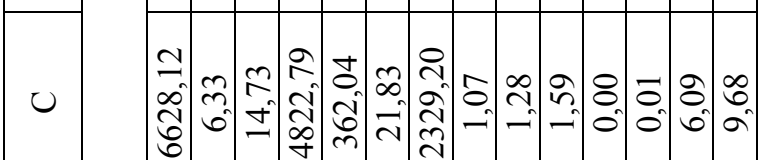

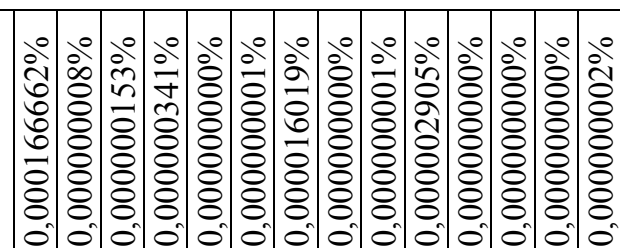

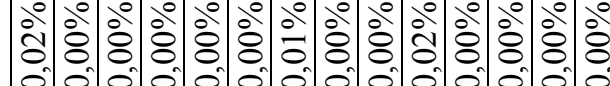

文

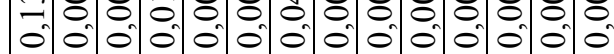

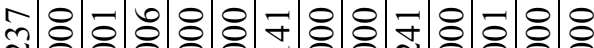

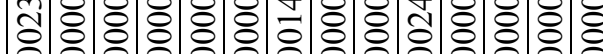

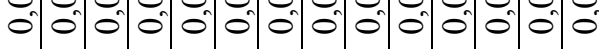

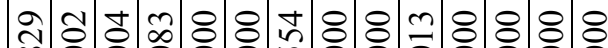

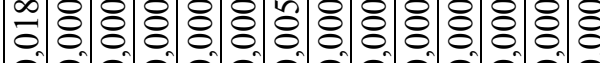

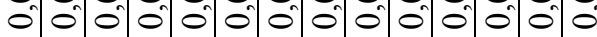

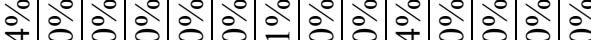
‘)

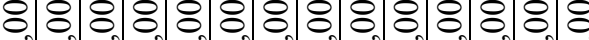

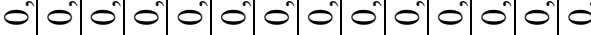

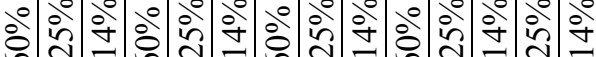

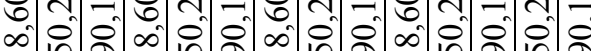

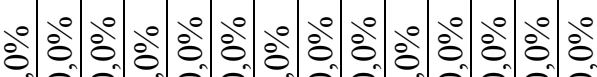
nी

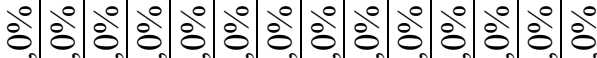
n n n n n n in in in in in in

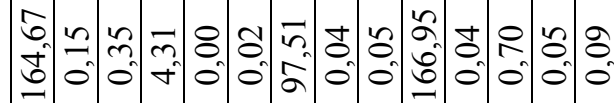

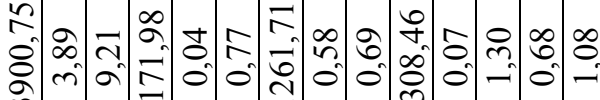

๓ :

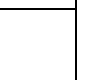

(

$\varangle$

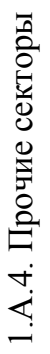

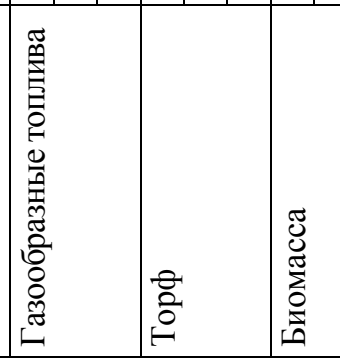

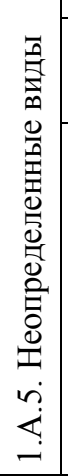

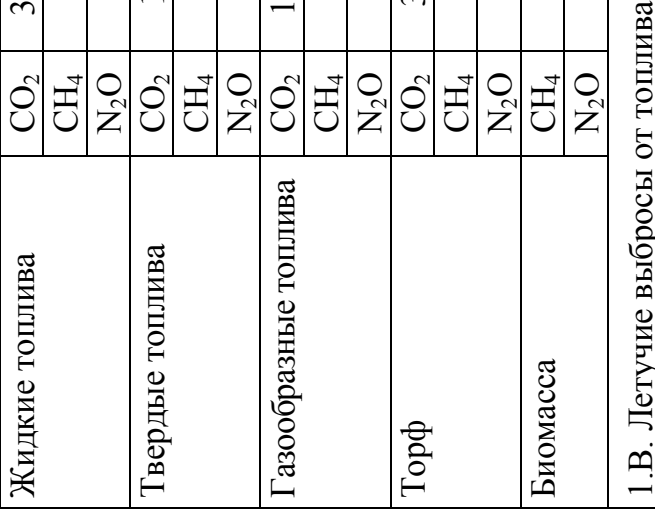


ㄴ.

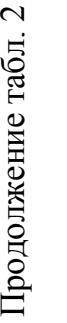
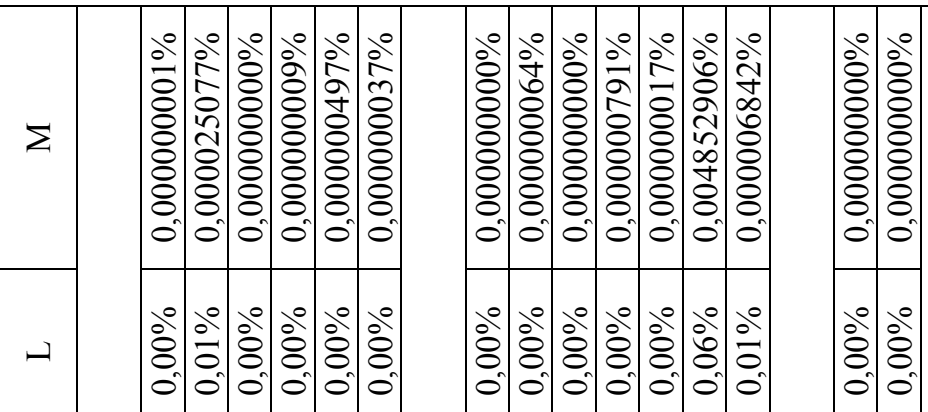

\begin{tabular}{|l|l|l|l|l|l|l|l}
\hline & & & & \\
\hline
\end{tabular}

客

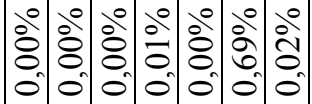

ㄱㅇ원

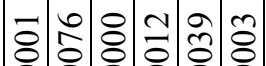

ㅇㅇㅇㅇㅇㅇㅇㅇㅇㅇㅇㅇㅛ

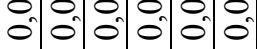

융융융유융

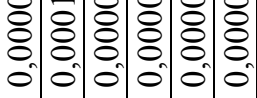

\begin{tabular}{llllll|l}
0 & 0 & 0 & 0 & 0 & 0 \\
\hline
\end{tabular}

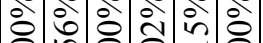

$I$

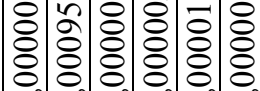

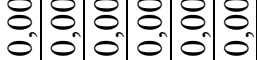

a a a $a_{0} a_{0} a_{0}$

穴

ชी

$\circ \circ \circ \circ \div 0$

I

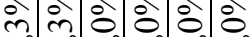

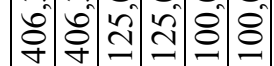

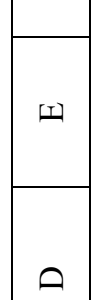

- 0.00

ठㅇ.

nी nी nी nी

กิ

० กิ

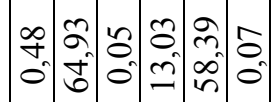

m

ㅇㅇㅇㅇㅇㅇํㅇ

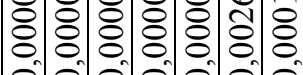

○.

$\circ \circ \circ \circ \circ \circ \circ$

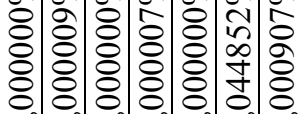

0. 00000000

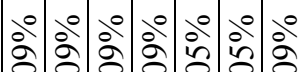

○े

ป

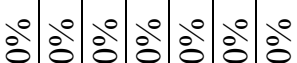

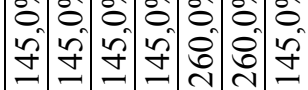

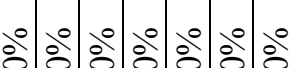

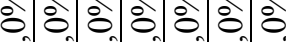

ת d

年

\begin{tabular}{l|l}
8 & 0 \\
0 & 0 \\
0 & 0
\end{tabular}

今̊ำ.

\begin{tabular}{|l|l|}
\hline 8 & 8 \\
8 & 8 \\
8 & 8 \\
8 & 8 \\
0 & 0 \\
\hline & 0 \\
\hline
\end{tabular}

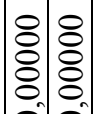

०. 0

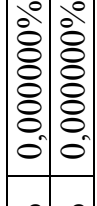

ํㅡ름ำ

nin

ㅇํㅇำ

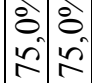

$\circ$

த̊ㅇำ

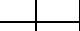

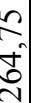

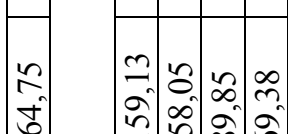

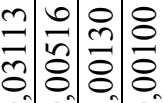

0.000

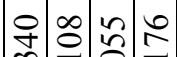

m

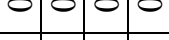

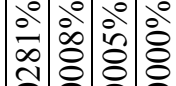

긍ㅇㅇㅇㅇㅇㅇㅇㅇㅇㅇㅇㅇ

苜

தे

年

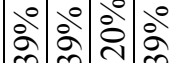

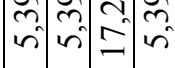

a.

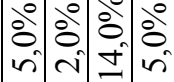

年

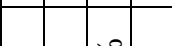

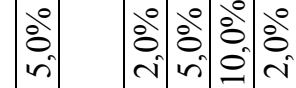

ปิ

8.

ヘิ

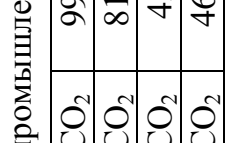

$\infty$

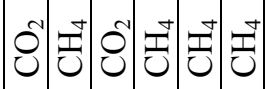

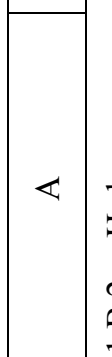

\section{\begin{tabular}{|l|l|l|l|l|}
\hline & & &
\end{tabular}}

西

중

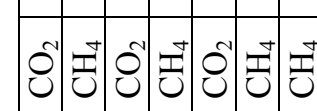

का

ठำ

\section{$\stackrel{8}{\mathscr{C}}$}

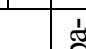

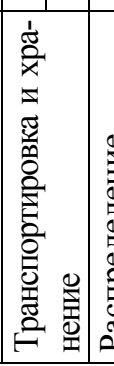

更

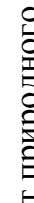

政

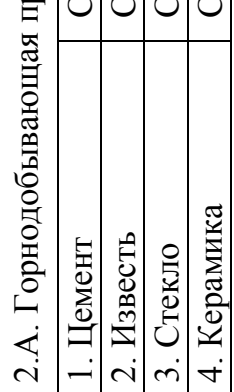

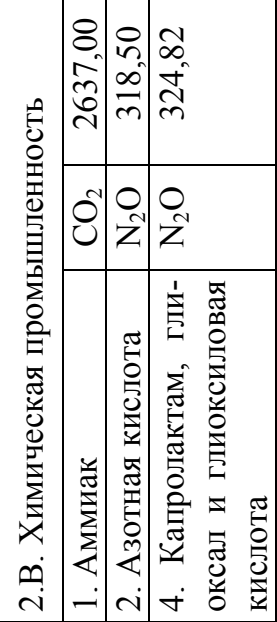




\begin{tabular}{|c|c|c|c|c|c|c|c|c|c|c|c|c|c|c|c|c|c|c|c|c|c|c|c|c|c|}
\hline$\Sigma$ & 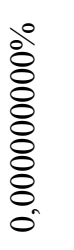 & $\mid$\begin{tabular}{|c}
0 \\
0 \\
$\hat{n}$ \\
$\hat{2}$ \\
0 \\
0 \\
8 \\
0 \\
0 \\
0 \\
0
\end{tabular} & $\begin{array}{l}0 \\
0 \\
2 \\
0 \\
8 \\
8 \\
0 \\
8 \\
8 \\
0 \\
0\end{array}$ & 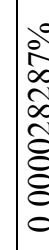 & 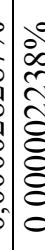 & & 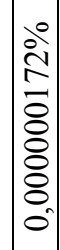 & $\begin{array}{l}0 \\
0 \\
i \\
8 \\
8 \\
8 \\
8 \\
8 \\
8 \\
8 \\
0 \\
0\end{array}$ & & & & & 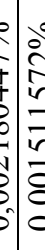 & 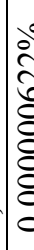 & 8 & $\begin{array}{l}0 \\
\vdots \\
\vdots \\
0 \\
0 \\
0 \\
0 \\
0 \\
0\end{array}$ & & & 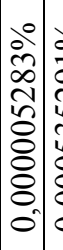 & 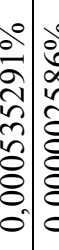 & 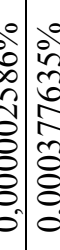 & $\begin{array}{l}0 \\
8 \\
8 \\
8 \\
8 \\
8 \\
8 \\
8 \\
8 \\
0 \\
0\end{array}$ & 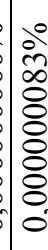 & & 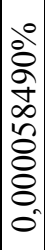 \\
\hline$\dashv$ & $\begin{array}{l}\delta_{0}^{\circ} \\
\delta_{0}\end{array}$ & 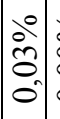 & 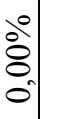 & $\stackrel{9}{0}$ & $a_{0}^{\circ}$ & & $\mid \begin{array}{l}0 \\
8 \\
8 \\
0 \\
0\end{array}$ & $\mid \begin{array}{l}0 \\
8 \\
0 \\
0 \\
0\end{array}$ & & & & वे & $\begin{array}{ll}0 \\
c \\
c\end{array}$ & 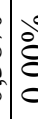 & $\frac{0}{0}$ & $\mid \begin{array}{l}0 \\
0 \\
0 \\
0\end{array}$ & & & 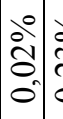 & 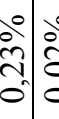 & $\begin{array}{lll}\circ \\
0 \\
0 \\
0\end{array}$ & : & : & & $\begin{array}{l}0 \\
0^{\circ} \\
0 \\
0 \\
0\end{array}$ \\
\hline$\forall$ & $\begin{array}{l}\delta_{0}^{\circ} \\
\delta_{0}\end{array}$ & $\left|\begin{array}{c}0 \\
\vdots \\
\dot{0} \\
0 \\
0\end{array}\right|$ & $\begin{array}{l}0 \\
8 \\
0 \\
0 \\
0\end{array}$ & ڤें & $a_{0}^{\circ}$ & & $\mid \begin{array}{l}0 \\
8 \\
0 \\
0 \\
0\end{array}$ & $\mid \begin{array}{l}0 \\
8 \\
0 \\
0 \\
0\end{array}$ & & & & छे & 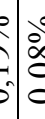 & 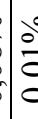 & $\Xi_{0}^{\circ}$ & $\frac{0^{\circ}}{0}$ & & & $\left|\begin{array}{c|c}0 \\
0 \\
0 \\
0 \\
0\end{array}\right|$ & \begin{tabular}{l|l}
0 \\
$\vdots$ \\
0 \\
0 \\
0
\end{tabular} & $\begin{array}{lll}8 \\
5 \\
\end{array}$ & & ठ․ & & 号 \\
\hline$r$ & $\begin{array}{l}8 \\
8 \\
0 \\
0 \\
0 \\
0\end{array}$ & $\left|\begin{array}{c}n \\
\hat{\sigma} \\
0 \\
0 \\
0\end{array}\right|$ & $\begin{array}{l}n \\
\vdots \\
\vdots \\
\vdots \\
0 \\
0\end{array}$ & ठิ & 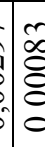 & & $\mid$\begin{tabular}{l}
$\infty$ \\
\hdashline \\
$\hat{\delta}$ \\
0 \\
0 \\
0
\end{tabular} & $\begin{array}{l}n \\
0 \\
0 \\
0 \\
0 \\
0\end{array}$ & & & & & 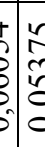 & 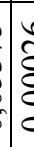 & $\frac{\sigma}{8}$ & $\mid$\begin{tabular}{l}
$\vec{n}$ \\
\hdashline \\
0 \\
0
\end{tabular} & & & $\mid$\begin{tabular}{l} 
\pm \\
\hdashline \\
0 \\
0 \\
0
\end{tabular} & $\begin{array}{l} \pm \\
\overline{8} \\
8 \\
0 \\
0\end{array}$ & 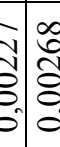 & \begin{tabular}{l|l} 
\\
$b$ \\
$b$ \\
$b$
\end{tabular} & . & & $\frac{8}{8}$ \\
\hline- & $\begin{array}{l}8 \\
\vdots \\
0 \\
0 \\
0 \\
0\end{array}$ & 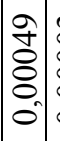 & 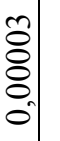 & $\begin{array}{l}\bar{m} \\
\bar{a} \\
0\end{array}$ & $\hat{\tilde{E}}$ & & $\mid \begin{array}{l}\delta \\
\delta \\
\delta \\
\delta \\
0 \\
0\end{array}$ & $\begin{array}{l}0 \\
\delta \\
\delta \\
0 \\
0 \\
0\end{array}$ & & & & & 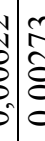 & 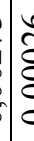 & 这 & 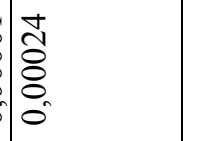 & & & $\mid \begin{array}{l}0 \\
0 \\
0 \\
0 \\
0 \\
0\end{array}$ & 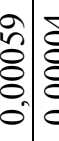 & $\begin{array}{l}5 \\
0 \\
0\end{array}$ & $\mid \begin{array}{l}\overline{8} \\
0 \\
0\end{array}$ & 定 & & : \\
\hline$I$ & $\begin{array}{l}\text { oे } \\
\text { oे } \\
8 \\
8 \\
0 \\
0\end{array}$ & $\mid \begin{array}{c}0 \\
\vdots \\
1 \\
\hat{0} \\
8 \\
0 \\
0 \\
0\end{array}$ & $\begin{array}{l}0 \\
8 \\
8 \\
\vdots \\
\vdots \\
0 \\
0 \\
0\end{array}$ & 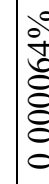 & $\mid \begin{array}{l}0 \\
\vdots \\
\vdots \\
\vdots \\
\vdots\end{array}$ & & $\begin{array}{l}0 \\
0 \\
0 \\
0 \\
8 \\
8 \\
0 \\
0 \\
0\end{array}$ & $\begin{array}{l}0 \\
8 \\
8 \\
8 \\
8 \\
8 \\
0 \\
0 \\
0\end{array}$ & & & & & $\left\{\begin{array}{l}0 \\
0 \\
0\end{array}\right.$ & 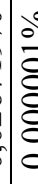 & 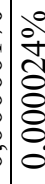 & 文 & & & 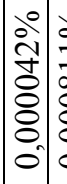 & 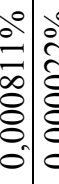 & 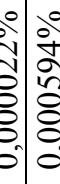 & $\begin{array}{l}0 \\
8 \\
8 \\
8 \\
8 \\
8 \\
0 \\
0 \\
0\end{array}$ & ठें & $\begin{array}{l}80 \\
8 \\
8 \\
8 \\
8 \\
8 \\
0\end{array}$ & $\begin{array}{l}\text { ¿ें } \\
\text { مे } \\
\text { } \\
8 \\
0 \\
0\end{array}$ \\
\hline 0 & $\begin{array}{l}\stackrel{0}{\circ} \\
\stackrel{0}{=} \\
=\end{array}$ & 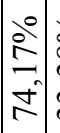 & 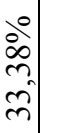 & $\begin{array}{l}\text { ठें } \\
\text { ठे } \\
\text { ते }\end{array}$ & $\left(\begin{array}{ll}0 \\
2\end{array}\right.$ & & 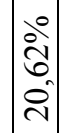 & 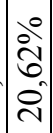 & & & & & $\dot{s}$ & 过 & $\left\{\begin{array}{l}0 \\
\partial \\
\partial \\
\hdashline\end{array}\right.$ & 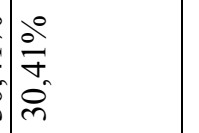 & & & $\mid \begin{array}{l}0 \\
0 \\
0 \\
0 \\
0 \\
0\end{array}$ & 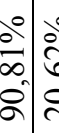 & 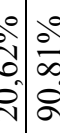 & 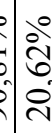 & $\left\{\begin{array}{l}0 \\
\frac{0}{\infty} \\
0 \\
8\end{array}\right.$ & & $\begin{array}{l}\frac{0}{\infty} \\
\infty \\
8 \\
8\end{array}$ \\
\hline I & $\begin{array}{l}\dot{\theta}^{\circ} \\
0 \\
0\end{array}$ & $\left|\begin{array}{l}0 \\
0 \\
0 \\
7 \\
7\end{array}\right|$ & 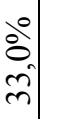 & $\begin{array}{l}8 \\
8 \\
4 \\
4\end{array}$ & $\left(\begin{array}{ll}0 \\
0 \\
2\end{array}\right.$ & & 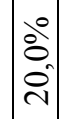 & $\mid \begin{array}{l}0 \\
8 \\
0 \\
\delta\end{array}$ & & & & वे & 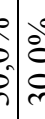 & 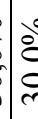 & $\left\{\begin{array}{l}0 \\
0 \\
0 \\
0\end{array}\right.$ & 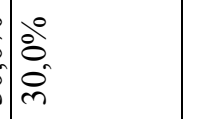 & & & & 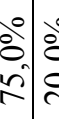 & $\begin{array}{lll}0 \\
0 \\
0 \\
0\end{array}$ & & $\left\{\begin{array}{l}0 \\
0 \\
i\end{array}\right.$ & & $\begin{array}{l}0 \\
0^{\circ} \\
i n\end{array}$ \\
\hline 디 & $\begin{array}{l}\text { 总 } \\
\text { in }\end{array}$ & 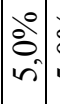 & 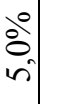 & dे & 8 & & $\begin{array}{l}0 \\
\text { oे } \\
\text { n. }\end{array}$ & $\left|\begin{array}{c}0 \\
0 \\
i\end{array}\right|$ & & & & & $\begin{array}{l}0 \\
:\end{array}$ & 8 & $\left\{\begin{array}{l}0 \\
0 \\
i\end{array}\right.$ & {$\left[\begin{array}{l}0 \\
\delta^{\circ}\end{array}\right.$} & & & \begin{tabular}{|c|c}
0 \\
0 \\
$\vdots$ \\
in
\end{tabular} & 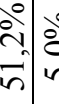 & 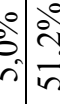 & & $\stackrel{\circ}{i n}$ & & $\frac{\circ}{i n}$ \\
\hline$\theta$ & $\begin{array}{l}\stackrel{0}{1} \\
\text { ô }\end{array}$ & 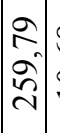 & $\begin{array}{l}\infty \\
0 \\
0 \\
0 \\
-\end{array}$ & $\begin{array}{l}\tilde{\alpha} \\
\tilde{z} \\
\varrho\end{array}$ & in & 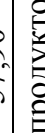 & 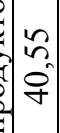 & ro & & & & & $=\hat{n}$ & & $\stackrel{2}{\beth}$ & $\begin{array}{l}\mathcal{I} \\
\sim \\
m\end{array}$ & & & 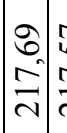 & 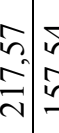 & 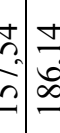 & & 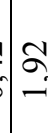 & & $\begin{array}{l}\stackrel{0}{0} \\
\text { N } \\
\text { r }\end{array}$ \\
\hline$U$ & $\mid \begin{array}{l}\infty \\
\infty \\
0 \\
0\end{array}$ & $\begin{array}{l}\infty \\
n \\
\ddots \\
m \\
m\end{array}$ & $\begin{array}{l}\simeq \\
\approx \\
=\end{array}$ & 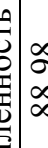 & $\left\{\begin{array}{l}n \\
n \\
n \\
n\end{array}\right.$ & 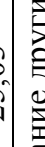 & 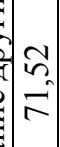 & 8 & & 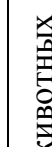 & & & 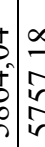 & కc & $\hat{\widetilde{J}}$ & $\begin{array}{l}2 \\
0 \\
0\end{array}$ & 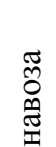 & & $\left.\mid \begin{array}{c|c}n & \\
n \\
\infty \\
0 \\
m \\
n\end{array}\right]$ & \begin{tabular}{l|l}
$\bar{m}$ & \\
$\vec{n}$ & \multirow{2}{c}{}
\end{tabular} & 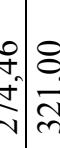 & $\stackrel{2}{\sigma}$ & $\stackrel{2}{\infty}$ & & $\begin{array}{l}\overrightarrow{0} \\
\dot{J} \\
\text { I }\end{array}$ \\
\hline$ص$ & ల̃ & $\overbrace{}^{2}$ & 志 & ל. & 要 & 音 & $\begin{array}{l}0 \\
z^{\prime}\end{array}$ & $\mid \frac{\omega}{\omega}$ & & 要 & 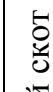 & & 跣 & 已 & 吾 & 式 & 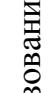 & $\begin{array}{l}\text { : } \\
\text { ond }\end{array}$ & 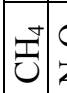 & 足 & 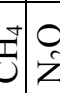 & $\vec{J}$ & $\left\{\begin{array}{l}0 \\
z\end{array}\right.$ & & $\stackrel{0}{O}$ \\
\hline$\varangle$ & 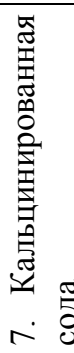 & 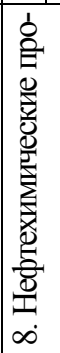 & 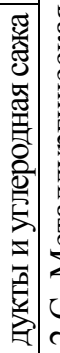 & 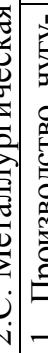 & 20 & $\begin{array}{ll}5 \\
0 \\
0 \\
0 \\
0 \\
0 \\
0 \\
0 \\
0 \\
0 \\
0 \\
0\end{array}$ & 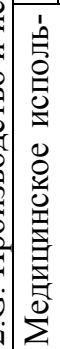 & 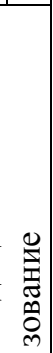 & 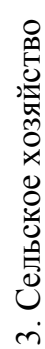 & 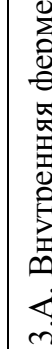 & 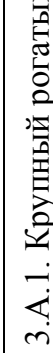 & S & 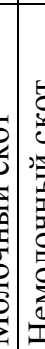 & 2 & 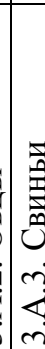 & 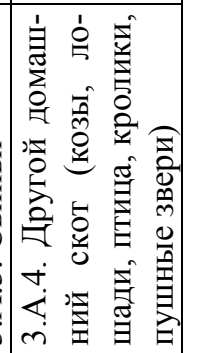 & 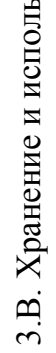 & 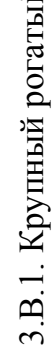 & 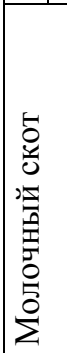 & & 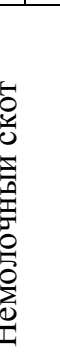 & 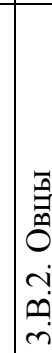 & & 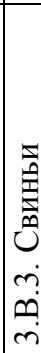 & \\
\hline
\end{tabular}




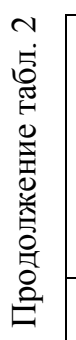

\begin{tabular}{|c|c|c|c|}
\hline$\Sigma$ & $\begin{array}{l}0 \\
\vdots \\
2 \\
\hat{n} \\
8 \\
8 \\
8 \\
8 \\
8 \\
0 \\
0\end{array}$ & 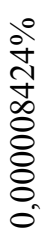 & 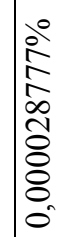 \\
\hline$\neg$ & $\begin{array}{l}\frac{0}{0} \\
0 \\
0\end{array}$ & $\begin{array}{l}\overbrace{}^{0} \\
\text { ஸे } \\
0\end{array}$ & 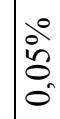 \\
\hline$\forall$ & $\mid \begin{array}{c}0 \\
8 \\
0 \\
0 \\
0\end{array}$ & $\frac{\partial^{0}}{0}$ & ठ̊. \\
\hline$\neg$ & $\mid \begin{array}{l}n \\
\hat{0} \\
8 \\
8 \\
0\end{array}$ & 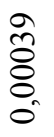 & $\begin{array}{l}\hat{n} \\
\frac{8}{8} \\
0\end{array}$ \\
\hline - & $\left|\begin{array}{l}0 \\
0 \\
8 \\
8 \\
0 \\
0\end{array}\right|$ & $\begin{array}{l}1 \\
8 \\
8 \\
0 \\
0\end{array}$ & $\begin{array}{l}\circ \\
8 \\
8 \\
8 \\
0 \\
0\end{array}$ \\
\hline$I$ & $\mid \begin{array}{c}0 \\
\stackrel{\circ}{0} \\
\delta \\
8 \\
8 \\
8 \\
0 \\
0\end{array}$ & $\begin{array}{l}\text { o̊ } \\
\text { m } \\
0 \\
8 \\
\delta \\
0 \\
0\end{array}$ & 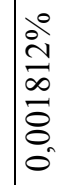 \\
\hline$\circlearrowleft$ & 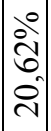 & 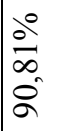 & 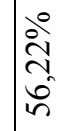 \\
\hline I & 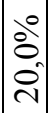 & $\begin{array}{l}\delta_{0}^{0} \\
\stackrel{n}{2}\end{array}$ & $\begin{array}{l}8^{0} \\
0^{\circ} \\
0^{\circ}\end{array}$ \\
\hline [工] & $\begin{array}{l}\AA_{0}^{0} \\
\hat{\sigma}^{2}\end{array}$ & ํํํ & $\begin{array}{l}\delta^{0} \\
\text { in }\end{array}$ \\
\hline ค & $\begin{array}{c}8 \\
\circ \\
\text { N }\end{array}$ & $\begin{array}{l}n \\
\text { ñ } \\
\text { ñ }\end{array}$ & $\frac{n}{n}$ \\
\hline$U$ & $\begin{array}{l}\infty \\
\infty \\
0 \\
0 \\
n\end{array}$ & $\begin{array}{l}\vec{n} \\
\hat{n} \\
\hat{n}\end{array}$ & 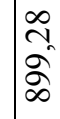 \\
\hline
\end{tabular}

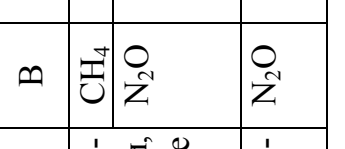

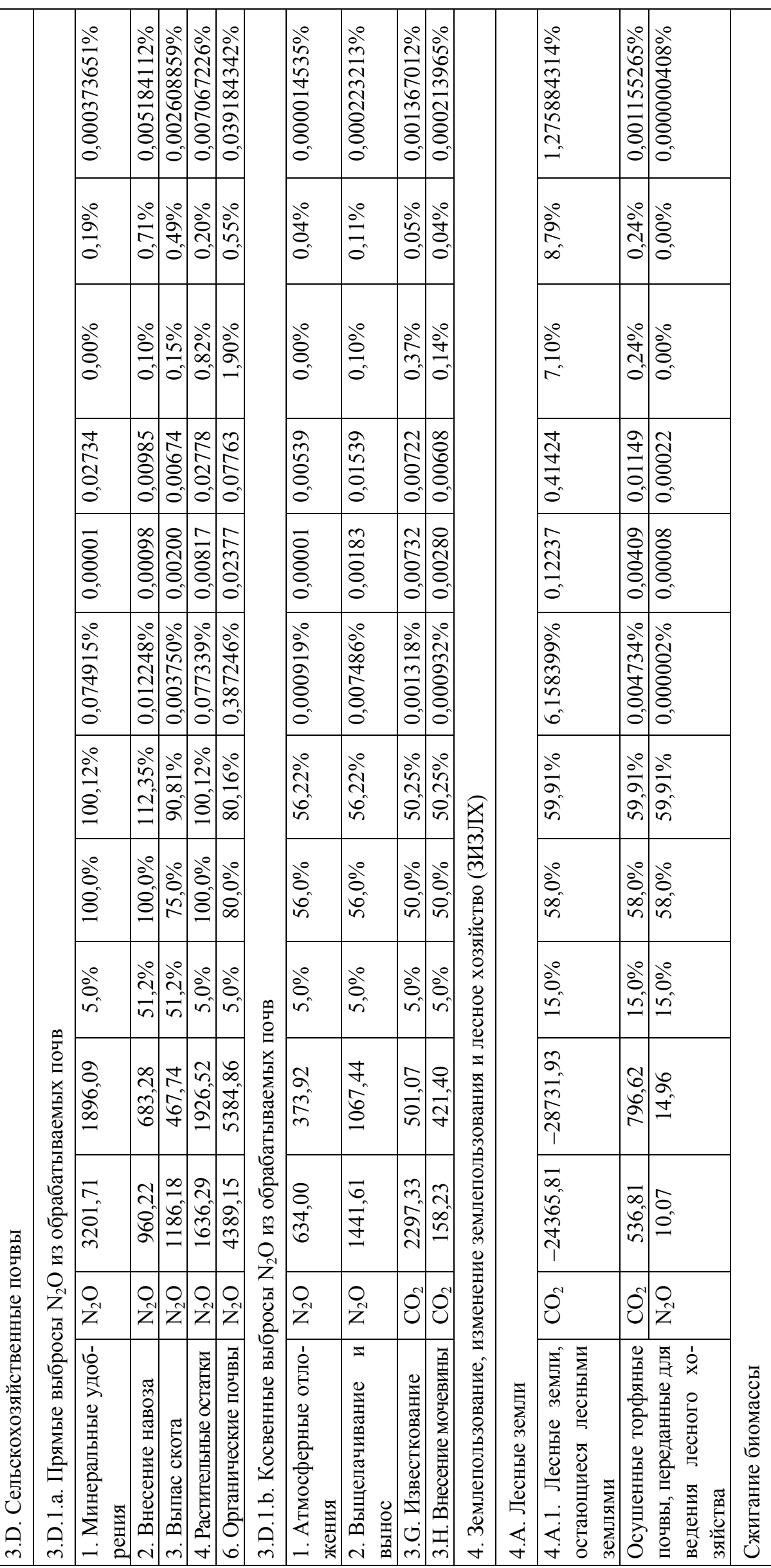




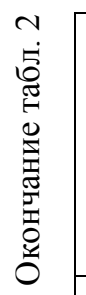

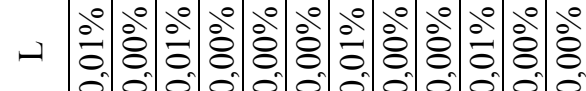

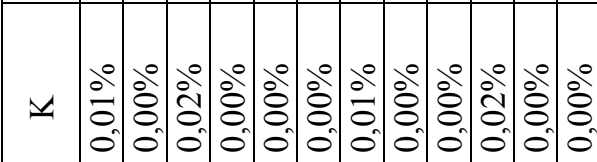

ปิ่)

-

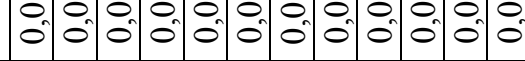

-

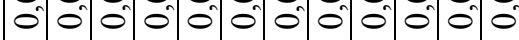

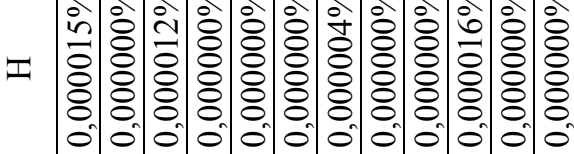

-

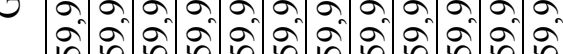

L

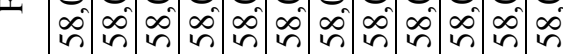

I

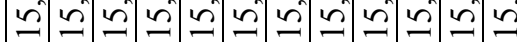

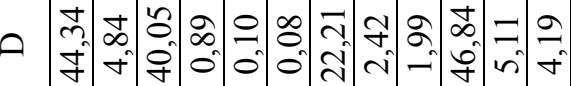

J

ली mं ठी

๓ రి

\begin{tabular}{|c|c|c|c|c|}
\hline$\varangle$ & 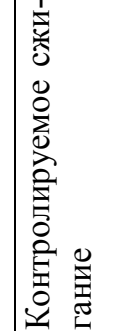 & 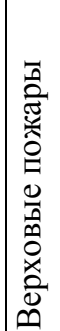 & 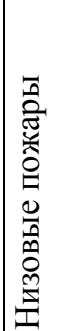 & 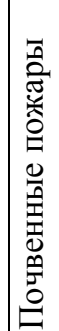 \\
\hline
\end{tabular}

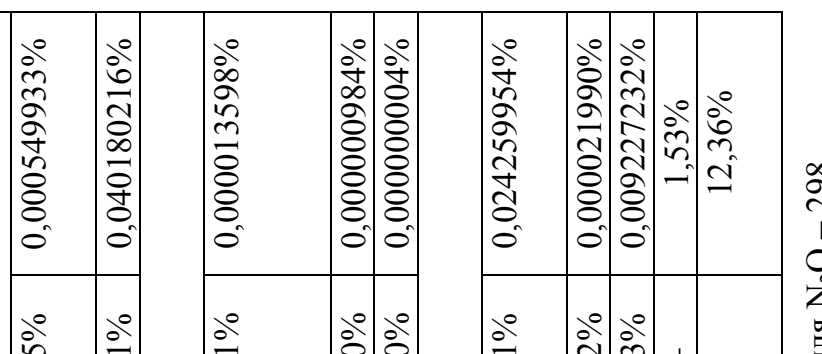

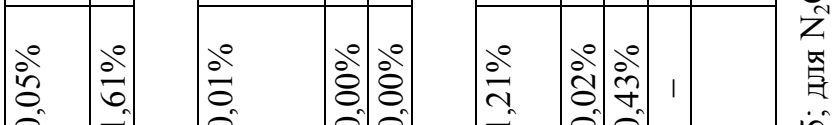

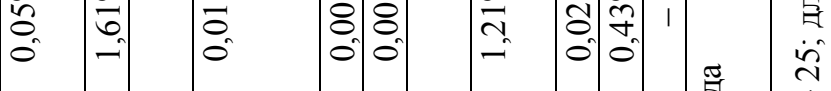

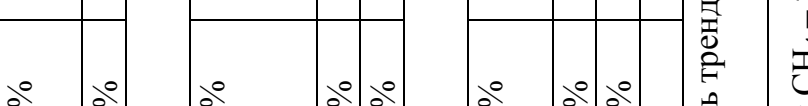

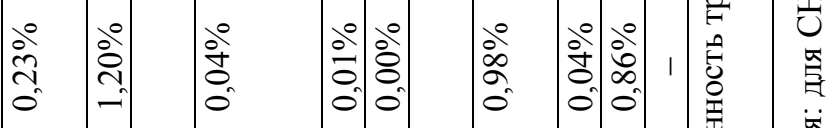

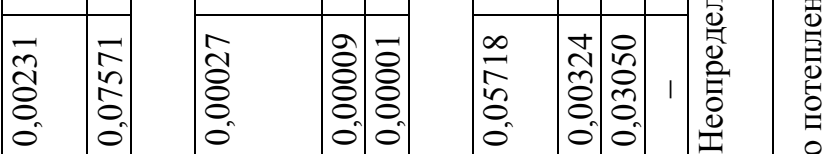

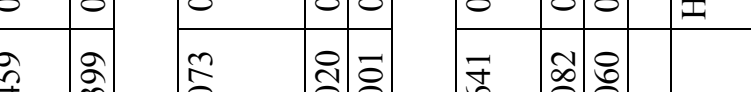

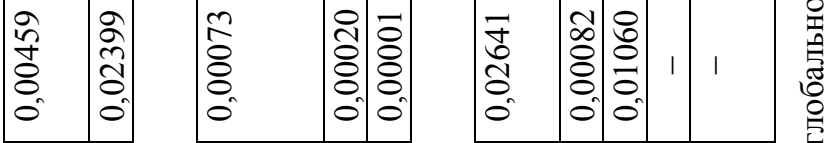

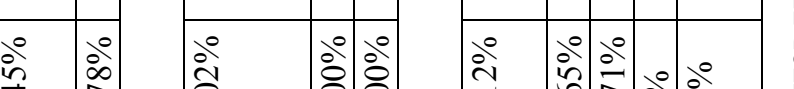

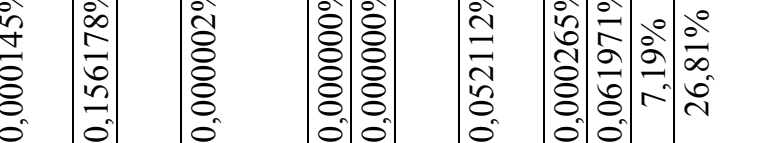

\begin{tabular}{ll|l|l|l|l|l|l|l|}
0 & 0 & 0 \\
0 & 0 & 0 & 0 \\
\hline
\end{tabular}

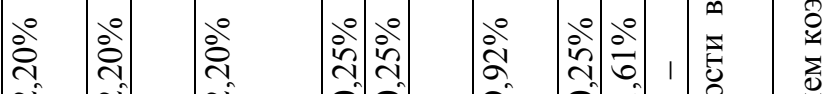

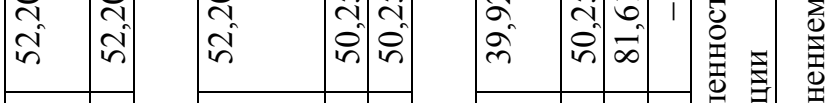

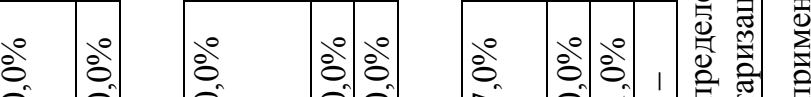

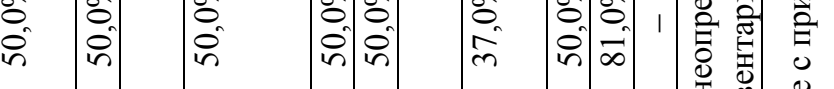

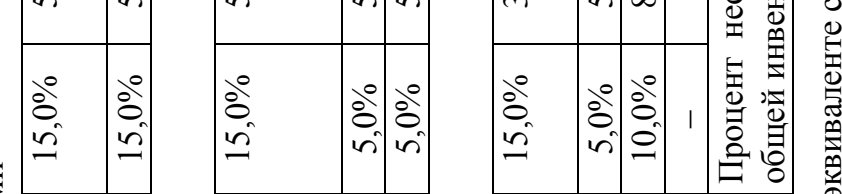

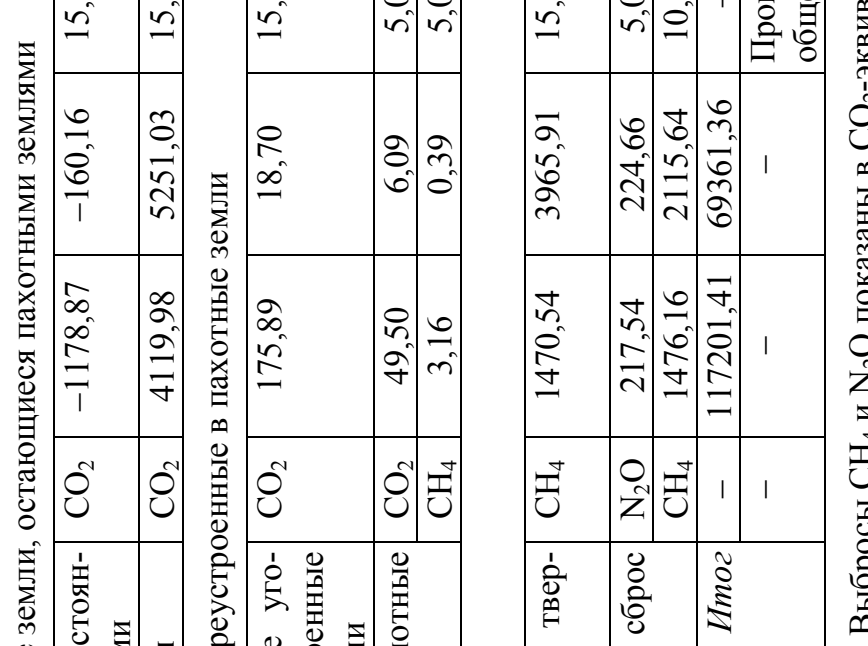

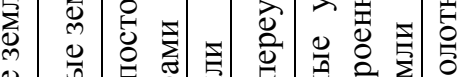

苟

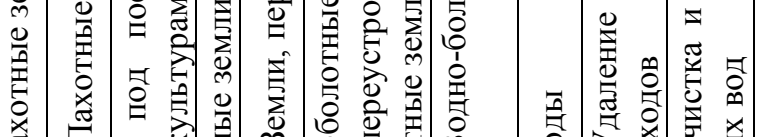

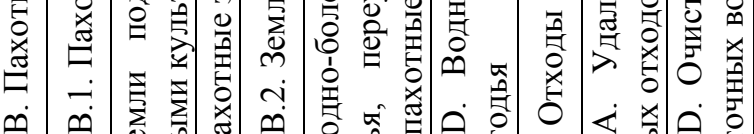

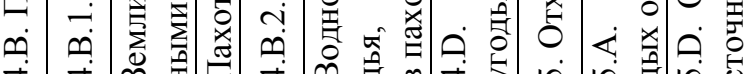


Примечание А. Если для какой-либо категории источников известна лишь суммарная неопределенность (не отдельно для коэффициента выбросов и для данных о деятельности) то:

- внести неопределенность в колонку F и внести 0 в колонку Е, если неопределенность коррелируется между годами;

- внести неопределенность в колонку Е и внести 0 в колонку $\mathrm{F}$, если неопределенность не коррелируется между годами.

Примечание B:

$$
G=\sqrt{E^{2}+F^{2}}
$$

Примечание C:

$$
H=\frac{(G D)^{2}}{\left(\sum D\right)^{2}} .
$$

Примечание D:

$$
I=\left|\begin{array}{c}
\frac{0,01 D_{x}+\sum D_{i}-\left(0,01 C_{x}+\sum C_{i}\right)}{\left(0,01 C_{x}+\sum C_{i}\right)} \times \\
\times 100-\frac{\sum D_{i}-\sum C_{i}}{\sum C_{i}} 100
\end{array}\right|,
$$

где $C_{x}, D_{x}$ - величина ряда $x$ таблицы из соответствующей колонки, представляющей определенную категорию; $\Sigma C_{i}, \Sigma D_{i}-$ сумма по всем категориям (рядам) кадастра соответствующей колонки.

Примечание Е:

$$
J=\left|\frac{D}{\sum C}\right| .
$$

Примечание F:

$$
K=I F \text {. }
$$

В случае, когда предполагается отсутствие корреляции между коэффициентами выбросов, должна использоваться чувствительность типа $\mathrm{B}$, а результат умножаться на $\sqrt{2}$ :

$$
K_{x}=J_{x} F_{x} \sqrt{2} .
$$

Примечание G:

$$
L=J E \sqrt{2}
$$

В случае, когда предполагается корреляция между данными о деятельности, должна использоваться чувствительность типа $\mathrm{A}$, a умножать результат на $\sqrt{2}$ не требуется:

$$
L_{x}=I_{x} E_{x} .
$$

Примечание $H$ :

$$
M=K^{2}+L^{2} .
$$

Таким образом, в табл. 2 рассчитаны неопределенности тренда и общей инвентаризации выбросов и поглощений парниковых газов для 2018 г. При удалении из расчетной таблицы категорий секторов «ППИП», «Сельское хозяйство», «ЗИЗЛХ» и «Отходы» неопределенность тренда и инвентаризации выбросов сектора «Энергетика» будет составлять 4,12 и 4,01\% соответственно. При оценке неопределенности тренда и общей инвентаризации выбросов без включения категорий сектора «Энергетика» показатели составят 149,30\% для неопределенности общей инвентаризации и $66,90 \%$ для неопределенности тренда.

Заключение. Проведенная оценка неопределенности тренда и общей инвентаризации выбросов и поглощений парниковых газов обеспечивают соответствие требованиям Руководящих принципов РКИК ООН для представления информации о годовых кадастрах парниковых газов. Неопределенности коэффициентов выбросов и данных о деятельности для категорий сектора «Энергетика» снижают общие неопределенностей тренда и инвентаризации благодаря тому, что Беларусь использует в энергетических целях преимущественно природный газ, а не другой более грязный вид ископаемого топлива. Переход на методики более высокого уровня наряду с использованием национальных коэффициентов выбросов способствует снижению общей неопределенности инвентаризации. Следует также отметить, что проведенное исследование улучшает национальную инвентаризацию выбросов и поглощений парниковых газов в соответствии с принципами рационального использования ресурсов.

\section{Список литературы}

1. Государственный кадастр антропогенных выбросов из источников и абсорбции поглотителями парниковых газов Республики Беларусь 1990-2001 гг. [Электронный ресурс] // Веб-сайт секретариата РКИК ООН. URL: https://unfccc.int/process/transparency-and-reporting/reporting-and-reviewunder-the-convention/greenhouse-gas-inventories/submissions-of-annual-greenhouse-gas-inventories-for2017/submissions-of-annual-ghg-inventories-2003 (дата обращения: 15.02.2021).

2. Об одобрении Рамочной конвенции Организации Объединенных Наций об изменении климата: Указ Президента Республики Беларусь от 10 апреля 2000 г. № 177 [Электронный ресурс] // Вебсайт Информационно-поисковой системы «ЭТАЛОН-ONLINE». URL: https:/etalonline.by/document/?regnum=p30000177\&q id=2118916 (дата обращения: 15.02.2021). 
3. Рамочная Конвенция об изменении климата Организации Объединенных Наций [Электронный ресурс] // Веб-сайт секретариата РКИК ОOH. URL: https://unfccc.int/files/essential_background/background publications htmlpdf/application/pdf/convru.pdf (дата обращения: 15.02.2021).

4. Решение Конференции Сторон Рамочной Конвенции об изменении климата Организации Объединенных Наций 24/CP.19 [Электронный ресурс] // Веб-сайт секретариата PКИК OOH. URL: https://unfccc.int/resource/docs/2013/cop19/rus/10a03r.pdf (дата обращения: 15.02.2021).

5. Отчет о рассмотрении инвентаризации 2019 [Электронный ресурс] // Веб-сайт секретариата РКИК ООН. URL: https://unfccc.int/sites/default/files/resource/arr2019_BLR.pdf (дата обращения: 15.02.2021).

6. Отчет о рассмотрении инвентаризации 2017 [Электронный ресурс] // Веб-сайт секретариата РКИК ООН. URL: https://unfccc.int/sites/default/files/resource/blr.pdf (дата обращения: 15.02.2021).

7. Энергетический баланс Республики Беларусь [Электронный ресурс] // Веб-сайт Национального статистического комитета Республики Беларусь. URL: https://www.belstat.gov.by/ofitsialnayastatistika/publications/izdania/public_compilation/index_17874/ (дата обращения: 15.02.2021).

8. Руководящие принципы проведения национальных инвентаризаций парниковых газов МГЭИК, 2006. Т. 2. Энергетика. Гл. 1. Введение [Электронный ресурс] // Веб-сайт Института глобальных экологических стратегий (Япония). URL: https://www.ipcc-nggip.iges.or.jp/public/2006gl/russian/pdf/2_Volume2/V2_1_Ch1_Introduction.pdf\#page=27 (дата обращения: 15.02.2021).

9. Государственный кадастр антропогенных выбросов из источников и абсорбции поглотителями парниковых газов Республики Беларусь 1990-2018 гг. [Электронный ресурс] // Веб-сайт секретариата РКИК ООН. URL: https://unfccc.int/ghg-inventories-annex-i-parties/2020 (дата обращения: 15.02.2021).

10. Руководящие принципы проведения национальных инвентаризаций парниковых газов МГЭИК, 2006. Т. 2. Энергетика. Гл. 1. Стационарное сжигание топлива [Электронный ресурс] // Веб-сайт Института глобальных экологических стратегий (Япония). URL: https://www.ipcc-nggip. iges.or.jp/public/2006gl/russian/pdf/2_Volume2/V2_2_Ch2_Stationary_Combustion.pdf\#page=40 (дата обращения: 15.02.2021).

11. Руководящие принципы проведения национальных инвентаризаций парниковых газов МГЭИК, 2006. Т. 1. Общие руководящие указания и отчетность. Гл. 4. Методологический выбор и определение ключевых категорий [Электронный ресурс] // Веб-сайт Института глобальных экологических стратегий (Япония). URL: https://www.ipcc-nggip.iges.or.jp/public/2006gl/russian/pdf/1_/V1_ 4_Ch4_MethodChoice.pdf\#page=8 (дата обращения: 15.02.2021).

12. Пересмотренные Руководящие принципы национальных кадастров парниковых газов МГЭИК, 1996. Приложение 1. Управление неопределенностями. [Электронный ресурс] // Веб-сайт Института глобальных экологических стратегий (Япония). URL: https://www.ipcc-nggip.iges.or.jp/ public/g1/guidelin/annex1ri.pdf\#page=4 (дата обращения: 15.02.2021).

13. Мелех Д. В. Переход на методологию уровня 2 при оценке выбросов диоксида углерода от стационарного сжигания природного газа // Природные ресурсы. 2020. № 2. С. 125-134.

14. База данных коэффициентов выбросов Межправительственной группы экспертов по изменению климата [Электронный ресурс] // Веб-сайт Института глобальных экологических стратегий (Япония). URL: https://www.ipcc-nggip.iges.or.jp/EFDB/main.php (дата обращения: 15.02.2021).

15. Руководящие принципы проведения национальных инвентаризаций парниковых газов МГЭИК, 2006. Т. 2. Энергетика. Гл. 4. Мобильное сжигание топлива [Электронный ресурс] // Вебсайт Института глобальных экологических стратегий (Япония). URL: https://www.ipcc-nggip.iges.or.jp/public/2006g1/russian/pdf/2_Volume2/V2_3_Ch3_Mobile_Combustion.pdf\#page=17 (дата обращения: 15.02.2021).

16. Руководящие принципы проведения национальных инвентаризаций парниковых газов МГЭИК, 2006. Т. 2. Энергетика. Гл. 5. Летучие выбросы [Электронный ресурс] // Веб-сайт Института глобальных экологических стратегий (Япония). URL: https://www.ipcc-nggip.iges.or.jp/ public/2006gl/russian/pdf/2_Volume2/V2_4_Ch4_Fugitive_Emissions.pdf\#page=59 (дата обращения: 15.02.2021).

17. Государственный кадастр антропогенных выбросов из источников и абсорбции поглотителями парниковых газов Республики Беларусь 1990-2014 гг. [Электронный ресурс] // Веб-сайт секретариата РКИК ООН. URL: https://unfccc.int/process/transparency-and-reporting/reporting-and-reviewunder-the-convention/greenhouse-gas-inventories/submissions-of-annual-greenhouse-gas-inventories-for2017/submissions-of-annual-ghg-inventories-2016 (дата обращения: 15.02.2021).

18. Государственный кадастр антропогенных выбросов из источников и абсорбции поглотителями парниковых газов Республики Беларусь 1990-2016 гг. [Электронный ресурс] // Веб-сайт сек- 
ретариата РКИК ООН. URL: https://unfccc.int/process-and-meetings/transparency-and-reporting/reporting-and-review-under-the-convention/greenhouse-gas-inventories-annex-i-parties/submissions/national-inventory-submissions-2018 (дата обращения: 15.02.2021).

\section{References}

1. Gosudarstvennyy kadastr antropogennykh vybrosov iz istochnikov $i$ absorbtsii poglotitelyami parnikovykh gazov Respubliki Belarus' 1990-2001 [The state cadastre of anthropogenic emissions from sources and absorption by sinks of greenhouse gases of the Republic of Belarus 1990-2001]. Available at: https://unfccc.int/process/transparency-and-reporting/reporting-and-review-under-the-convention/greenhouse-gasinventories/submissions-of-annual-greenhouse-gas-inventories-for-2017/submissions-of-annual-ghg-inventories2003 (accessed 15.02.2021).

2. Ob odobrenii Ramochnoy konventsii Organizatsii Ob'yedinennykh Natsiy ob izmenenii klimata: Ukaz Prezidenta Resp. Belarus', 10.04.2000, № 177 [On approval of the United Nations Framework Convention on Climate Change: Decree of the President of the Republic of Belarus, 10.04.2000 No. 177]. Available at: https://etalonline.by/document/?regnum=p30000177\&q id=2118916 (accessed 15.02.2021).

3. Ramochnaya Konventsiya ob izmenenii klimata Organizatsii Ob'yedinennykh Natsiy [United Nations Framework Convention on Climate Change]. Available at: https://unfccc.int/files/essential_background/background_publications_htmlpdf/application/pdf/conveng.pdf. (accessed 15.02.2021).

4. Resheniye Konferentsii Storon Ramochnoy Konventsii ob izmenenii klimata Organizatsii Ob"yedinennykh Natsiy 24/CP.19 [Decision of the Conference of the Parties to the United Nations Framework Convention on Climate Change 24/CP.19]. Available at: https://unfccc.int/resource/docs/2013/cop19/eng/10a03.pdf\#page $=2$ (accessed 15.02.2021).

5. Otchet o rassmotrenii inventarizatsii 2019 [Inventory Review Reports 2019]. Available at: https://unfccc.int/sites/default/files/resource/arr2019 BLR.pdf (accessed 15.02.2021).

6. Otchet o rassmotrenii inventarizatsii $201 \overline{7}$ [Inventory Review Reports 2017]. Available at: https://unfccc.int/sites/default/files/resource/blr.pdf (accessed 15.02.2021).

7. Energeticheskiy balans Respubliki Belarus' [Energy balance of the Republic of Belarus]. Available at: https://www.belstat.gov.by/ofitsialnaya-statistika/publications/izdania/public_compilation/index_17874/ (accessed 15.02.2021).

8. Rukovodyashchiye printsipy provedeniya natsional'nykh inventarizatsiy parnikovykh gazov MGEIK, 2006. T. 2. Energetika. Gl. 1. Vvedeniye [Guidelines for National Greenhouse Gas Inventories IPCC, 2006. V. 2 Energy. Ch. 1. Introduction]. Available at: https://www.ipcc-nggip.iges.or.jp/public/2006gl/russian/pdf/2_Volume2/V2_1_Ch1_Introduction.pdf\#page=27 (accessed 15.02.2021).

9. Gosudarstvennyy kǟastr antropogennykh vybrosov iz istochnikov i absorbtsii poglotitelyami parnikovykh gazov Respubliki Belarus' 1990-2018 gg. [The state cadastre of anthropogenic emissions from sources and absorption by sinks of greenhouse gases of the Republic of Belarus 1990-2018]. Available at: https://unfccc.int/ghg-inventories-annex-i-parties/2020 (accessed 15.02.2021).

10. Rukovodyashchiye printsipy provedeniya natsional'nykh inventarizatsiy parnikovykh gazov MGEIK, 2006. T. 2. Energetika. Gl. 1. Statsionarnoye szhiganiye topliva [Guidelines for National Greenhouse Gas Inventories IPCC, 2006. V. 2 Energy. Ch. 2. Stationary Combustion]. Available at: https:// www.ipcc-nggip.iges.or.jp/public/2006g1/russian/pdf/2_Volume2/V2_2_Ch2_Stationary_Combustion.pdf\#page=40 (accessed 15.02.2021).

11. Rukovodyashchiye printsipy provedeniya natsional'nykh inventarizatsiy parnikovykh gazov MGEIK, 2006. T. 1. Obshchiye rukovodyashchiye ukazaniya i otchetnost'. Gl. 4. Metodologicheskiy vybor i opredeleniye klyuchevykh kategoriy [Guidelines for National Greenhouse Gas Inventories IPCC, 2006. V. 1 General Guidance and Reporting. Ch. 4. Methodological Choice and Identification of Key Categories]. Available at: https://www.ipcc-nggip.iges.or.jp/public/2006gl/russian/pdf/1_Volume1/V1_4_Ch4_MethodChoice.pdf\#page $=8$ (accessed 15.02.2021).

12. Peresmotrennyye Rukovodyashchiye printsipy natsional'nykh kadastrov parnikovykh gazov MGEIK, 1996. Prilozheniye 1. Upravleniye neopredelennostyami [Revised Guidelines for National Greenhouse Gas Inventories IPCC, 1996. Annex 1. Managing Uncertainties]. Available at: https://www.ipccnggip.iges.or.jp/public/g1/guidelin/annex1ri.pdf\#page=4 (accessed 15.02.2021).

13. Melekh D. V. Transition to the Tier 2 Methodology for Estimating Carbon Dioxide Emissions from Statoinary Combustion of Natural Gas. Prirodnyye resursy [Natural Resources], 2020, no. 2, pp. 125-314.

14. Baza dannykh koeffitsiyentov vybrosov Mezhpravitel'stvennoy gruppy ekspertov po izmeneniyu klimata [Emission Factor Database of Intergovernmental Panel on Climate Change]. Available at: https://www.ipcc-nggip.iges.or.jp/EFDB/main.php (accessed 15.02.2021). 
15. Rukovodyashchiye printsipy provedeniya natsional'nykh inventarizatsiy parnikovykh gazov MGEIK, 2006. T. 2. Energetika. Gl. 4. Mobil'noye szhiganiye topliva [Guidelines for National Greenhouse Gas Inventories IPCC, 2006. V. 2 Energy. Ch. 4. Mobile Combustion]. Available at: https://www.ipccnggip.iges.or.jp/public/2006gl/russian/pdf/2_Volume2/V2_3_Ch3_Mobile_Combustion.pdf\#page=17 (accessed 15.02.2021).

16. Rukovodyashchiye printsipy provedeniya natsional'nykh inventarizatsiy parnikovykh gazov MGEIK, 2006. T. 2. Energetika. Gl. 5. Letuchiye vybrosy [Guidelines for National Greenhouse Gas Inventories IPCC, 2006. V. 2 Energy. Ch. 5. Fugitive Emissions]. Available at: https://www.ipcc-nggip.iges.or.jp/ public/2006gl/russian/pdf/2_Volume2/V2_4_Ch4_Fugitive_Emissions.pdf\#page=59 (accessed 15.02.2021).

17. Gosudarstvennyy kadastr antropogennyk $h$ vybrosov iz istochnikov i absorbtsii poglotitelyami parnikovykh gazov Respubliki Belarus' 1990-2014 [The state cadastre of anthropogenic emissions from sources and absorption by sinks of greenhouse gases of the Republic of Belarus 1990-2014]. Available at: https://unfccc.int/process/transparency-and-reporting/reporting-and-review-under-the-convention/greenhousegas-inventories/submissions-of-annual-greenhouse-gas-inventories-for-2017/submissions-of-annual-ghg-inventories-2016 (accessed 15.02.2021).

18. Gosudarstvennyy kadastr antropogennykh vybrosov iz istochnikov i absorbtsii poglotitelyami parnikovykh gazov Respubliki Belarus' 1990-2016 [The state cadastre of anthropogenic emissions from sources and absorption by sinks of greenhouse gases of the Republic of Belarus 1990-2016]. Available at: https://unfccc.int/process-and-meetings/transparency-and-reporting/reporting-and-review-under-the-convention/ greenhouse-gas-inventories-annex-i-parties/submissions/national-inventory-submissions-2018 (accessed 15.02.2021).

\section{Информация об авторах}

Мелех Дмитрий Владимирович - заместитель заведующего отделом международного научного сотрудничества. Республиканское научно-исследовательское унитарное предприятие «Бел НИЦ «Экология» (220095, г. Минск, ул. Якубова, 76, Республика Беларусь). E-mail: melekhdima@gmail.com

Гончар Кристина Викторовна - научный сотрудник отдела международного научного сотрудничества. Республиканское научно-исследовательское унитарное предприятие «Бел НИЦ «Экология» (220095, г. Минск, ул. Якубова, 76, Республика Беларусь). E-mail: gonchar.kristina@mail.ru

Наркевич Иван Петрович - доктор технических наук, доцент, заведующий отделом международного научного сотрудничества. Республиканское научно-исследовательское унитарное предприятие «Бел НИЦ «Экология» (220095, г. Минск, ул. Якубова, 76, Республика Беларусь). E-mail: ivan.narkevitch@mail.ru

\section{Information about the authors}

Melekh Dzmitry Vladimirovich - Deputy Head of the Department of International Scientific Cooperation. Republican Research Unitary Enterprise "Belarusian Research Center "Ecology" (76, Yakubova str., 220095, Minsk, Republic of Belarus).E-mail: melekhdima@gmail.com

Gonchar Kristina Viktorovna - Researcher of the Department of International Scientific Cooperation. Republican Research Unitary Enterprise "Belarusian Research Center "Ecology" (76, Yakubova str., 220095, Minsk, Republic of Belarus). E-mail: gonchar.kristina@mail.ru

Narkevitch Ivan Petrovich - DSc (Engineering), Associate Professor, Head of the Department of International Scientific Cooperation. Republican Research Unitary Enterprise "Belarusian Research Center "Ecology" (76, Yakubova str., 220095, Minsk, Republic of Belarus). E-mail: ivan.narkevitch@mail.ru 